\title{
Carbon quantum dot supported semiconductor photocatalysts for efficient degradation of organic pollutants in water: A review
}

Sheetal Sharma ${ }^{a}$, Vishal Dutta ${ }^{a}$, Pardeep Singh ${ }^{a *, b}$, Pankaj Raizada ${ }^{a, b}$, Abolfazl Rahmani-

Sani $^{c, * *}$, Ahmad Hosseini-Bandegharaei ${ }^{c, d}$, Vijay Kumar Thakur ${ }^{e}$

${ }^{a}$ School of Chemistry, Faculty of Basic Sciences, Shoolini University, Solan (Himachal Pradesh)-

173212, India

${ }^{b}$ Himalayan Centre for Excellence in Nanotechnology, Shoolini University. Solan (HP) India173229

${ }^{c}$ Department of Environmental Health Engineering, Faculty of Health, Sabzevar University of Medical Sciences, Sabzevar, Iran

${ }^{d}$ Department of Engineering, Kashmar Branch, Islamic Azad University, PO Box 161, Kashmar, Iran

${ }^{\mathrm{e}}$ Enhanced Composites and Structures Center, School of Aerospace, Transport and Manufacturing, Cranfield University, Bedfordshire MK43 OAL, UK

Corresponding Authors:

*Pardeep Singh (Email: pardeepchem@gmail.com)

Tel: +91-1792-308000,

Fax: +91-1792-30800

**Abolfazl Rahmani-Sani (rahmani240@gmail.com) 


\begin{abstract}
Semiconductor photocatalyst mediated advanced oxidation processes are regarded as one of the most efficient technologies to mitigate organic pollutants in water. However, poor activity under visible light and the recombination of photogenerated electron and hole pairs hinder large scale applicability of semiconductor photocatalysts for water purification. The modification of semiconductor photocatalysts with carbon quantum dots (CQDs) is of high importance due to low toxicity, aqueous stability, enhanced surface area, economic feasibility, good biocompatibility and chemical inertness of CQDs. In this review, we highlight strategies to improve the activity of conventional semiconductor photocatalysts via coupling with CQDs. The enhanced photocatalytic activity of CQD modified narrow and wide band gap photocatalysts is due mainly to up-conversion photoluminescence (UPCL) and the electron reservoir properties of CQDs, while in the case of Z-scheme photocatalysts CQDs act as an electron mediator. Finally, a conclusive outlook and suggested research directions are provided to address challenges such as the inadequate separation of photoinduced charge carriers.
\end{abstract}

Keywords: Semiconductor photocatalysis; Limitations of conventional photocatalysts; Carbon quantum dots modified photocatalysts; Improved photocatalytic activity; Wastewater treatment 
Graphical Abstract

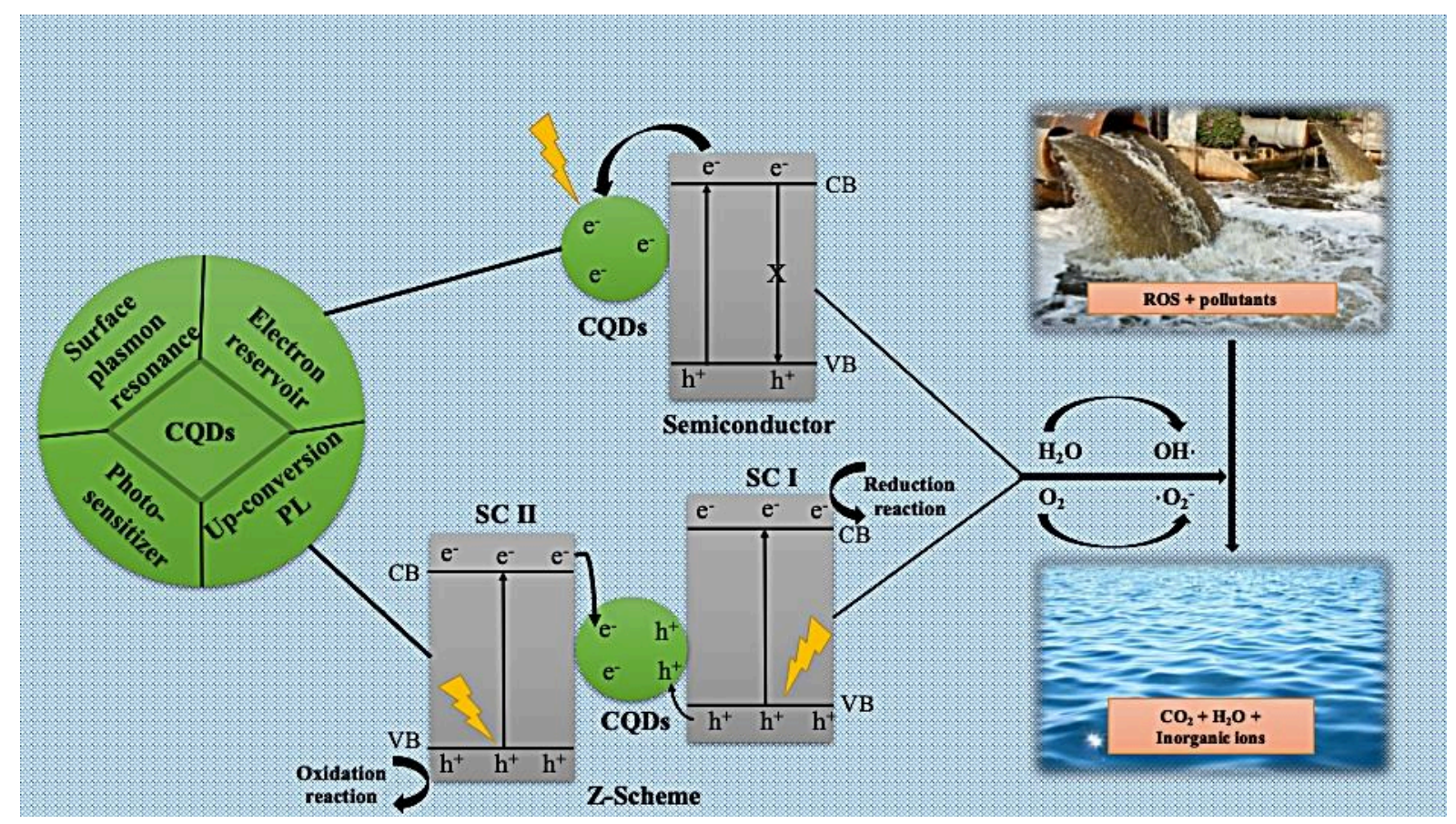




\section{Highlights}

- Overview of recent development in Carbon Quantum dots (CQDs) based photocatalysis.

- Integration of CQDs with other photocatalysts for enhanced photocatalysis.

- Elaboration of CQD's role in enhanced photocatalytic water purification.

- Future scope of CQDs based photocatalyst in wastewater treatment. 


\section{Abbreviations}

AOPs : Advanced oxidation processes; Ag: Silver; •Ag: Silver radical; $\mathrm{Ag}_{2} \mathrm{O}$ : Silver oxide; ARS: Alizarin red S; BDA: Butanediamine; $\mathrm{Bi}_{2} \mathrm{O}_{2} \mathrm{CO}_{3}$ : Bismuth subcarbonate; BiOBr: Bismuth oxybromide; BiOCl: Bismuth oxychloride; BiOX: Bismuth oxyhalide; BiOI: Bismuth oxyiodide; BPA: Bisphenol A; CdS: Cadmium sulphide; CQDs: Carbon quantum dots; $\mathrm{CCl}_{4}$ : Carbon tetrachloride; CIP: Ciprofloxacin; CV: Crystal violet; DEA: Diethylamine; DCM: Dichloromethane; eV: Electron volt ; $\mathrm{e}^{-}$: Electron; EDTA: Ethylene diamine tetra acetic acid; $\mathrm{Fe}_{2} \mathrm{O}_{3}$ :Ferric oxide; GQDs: Graphene quantum dots; $\mathrm{h}^{+}$: Hole; $\mathrm{H}_{2} \mathrm{O}_{2}$ :Hydrogen peroxide; $\bullet \mathrm{OH}$ : Hydroxyl radical; MO: Methylene orange; MB: Methylene; MV: Methylene violet; mA: Micro ampere; $\mathrm{KH}_{2} \mathrm{PO}_{4}$ :Mono potassium phosphate; NAC: $\mathrm{N}$ - acetyl- L- cysteine; $\mathrm{NA}_{2} \mathrm{HPO}_{4}$ : Disodium phosphate; NIR: Near infrared; $\mathrm{HNO}_{3}$ : Nitric acid; N-CQDs: Nitrogen doped carbon quantum dots; $\mathrm{O}_{2}$ : Oxygen; $\bullet \mathrm{O}_{2}$ :Oxygen radical; PEG: Polyethylene glycol; PL: Photoluminescence; PEG: Polyethylene glycol; PNP: p-nitrophenol ; Ph R: Phenol red; ROS: Reactive oxygen species; rpm: Revolutions per minute; Rh B: Rhodamine B; RT: Room temperature; $\mathrm{SiO}_{2}$ : Silicon dioxide; $\mathrm{CH}_{3} \mathrm{COOAg}$ : Silver acetate; $\mathrm{Ag}_{3} \mathrm{PO}_{4}$ : Silver phosphate; $\mathrm{H}_{2} \mathrm{SO}_{4}$ : Sulphuric acid; TEA: Triethylamine; TC: Tetracycline 


\section{Introduction}

Environmental pollution has been a major concern for human health with intense industrial development (Zhang et al., 2017; Raizada et al., 2017a). The concerns allied with harmful and toxic pollutants in water bodies have attracted global consideration (Raizada et al., 2017a; Singh et al., 2013a). The disposal of chemicals has led to contamination of lakes, rivers, oceans and groundwater aquifers (Sudhaik et al., 2018a; Gupta et al., 2014). Multifarious exactor pollutants are identified in the aquatic environment, such as surfactants, textile dyes, heavy metals, insecticides, and pesticides (Oliveira et al., 2010). Much research has focused on the exclusion of harmful contaminants from polluted waters and to abate their hazardous effect on ecosystems (Priya et al., 2016; Raizada et al., 2016a). Till now, various conventional methods like filtration, reverse osmosis, sedimentation, adsorption, biological and chemical techniques, coagulation, etc. have been extensively used for water decontamination (Sharma et al., 2018; Singh et al., 2016). However, the efficacy of these technologies is not satisfactory for the treatment of wastewater which contains multifarious contaminants such as organic solvents, pharmaceutical wastes, pesticides, and domiciliary chemicals (Singh et al., 2017; Sudhaik et al., 2018b). In the case of adsorption, activated carbons are usually used in adsorption of a wideranging array of water contaminants, but its adsorbent capability gradually diminishes as the number of cycles increases (Shandilya et al., 2018; Priya et al., 2016). Also, regeneration of traditional adsorbents requires a vacuum or steam source and major by-products generated can lessen the efficacy of the process. Under normal conditions, reverse osmosis has an extreme level of refusal for strong electrolytic solutes at high concentrations. In addition, ion-exchange produces an excessive amount of harmful wastes, and the treatment process uses a large amount of energy and materials and is therefore restricted (Singh et al., 2018a; Hasija et al., 2019). 
Recently, advanced oxidation processes (AOPs) have drawn attention in treating wastewater because of their capability in the degradation of a wide range of organic chemicals (Pare et al., 2008b; Shandilya et al., 2018). Among AOPs, visible light assisted oxidation processes have attracted tremendous attention due to good stability, low cost, energy efficiency, and eco-friendly nature (Raizada et al., 2018a). This technique has been exploited for remediation of a wide range of aqueous contaminants in water over the past 30 years (Raizada et al., 2017b). Under light absorption, pollutant molecules pass off photo-oxidative reactions which cleave contaminants into small molecular weight substances and change their chemical, mechanical and physical properties to generate innocuous products (Antoniadou et al., 2011).

The main roadblocks limiting wide-scale acceptance of this process are the insufficiency of commercially available visible light absorbing photocatalyst materials and ineffective separation of photogenerated electron and hole pairs (Sudhaik et al., 2018). The development of commercially accessible and absolute visible light absorbing photocatalyst is a crucial step in the efficient degradation of water pollutants (Raizada et al., 2019a; Benotte et al., 2008). During last four decades, various semiconductor photocatalyst like $\mathrm{Ag}_{3} \mathrm{PO}_{4}, \mathrm{BiOBr}, \mathrm{BiOCl}, \mathrm{BiOI}, \mathrm{AgI}$, $\mathrm{ZnFe}_{2} \mathrm{O}_{4}, \mathrm{COFe}_{2} \mathrm{O}_{4}, \mathrm{BiVO}_{4}, \mathrm{Ta}_{3} \mathrm{~N}_{5}, \mathrm{MnFe}_{2} \mathrm{O}_{4}, \mathrm{CaFe}_{2} \mathrm{O}_{4}, \mathrm{BiFe}_{2} \mathrm{O}_{4}, \mathrm{TaON}, \mathrm{g}-\mathrm{C}_{3} \mathrm{~N}_{4}, \mathrm{ZrO}_{2}$, etc. have been used as photocatalysts for degradation of contaminants and their number is constantly growing (Raizada et al., 2014a; Gautam et al., 2017). Band gap is an important parameter in defining the applicability of a semiconductor in a specific photocatalytic reaction. The fundamental principle of semiconductor photocatalyst relies on $\mathrm{e}^{-} / \mathrm{h}^{+}$excitation. The electrons in wide band gap $\left(\mathrm{E}_{\mathrm{g}} \geq 3 \mathrm{eV}\right)$ semiconductor photocatalysts could be excited only through UV light as they demand additional energy for electron excitation. On the other hand, electrons in narrow band gap $\left(\mathrm{E}_{\mathrm{g}} \leq 3 \mathrm{eV}\right)$ semiconductor photocatalysts could be excited by visible light as they 
don't need additional energy for electron excitation. Also, the electrons in narrow band gap semiconductor photocatalysts undergo fast recombination of photo-generated charge carriers (Raizada et al., 2016a). Non-natural UV resources are costly and UV light demands more protection for their utilization in water purification (Singh et al., 2013; Singh et al., 2018a). Some other limitations of unmodified photocatalysts have been stated like low degradation kinetics, deficient mineralization of contaminants, and accumulation of catalyst particles in liquid solution (Jamwal et al.,2015; Raizada et al., 2019c).

To overcome the above shortcomings, various strategies like immobilization of photocatalysts onto organic/inorganic support materials such as ceramics, activated carbon, and zeolites have been investigated (Raizada et al., 2016b; Singh et al., 2018b). These methods result in less agglomeration of the photocatalyst in a reaction solution. Moreover, the fabrication of magnetically recoverable and competent photocatalysts is another area of interest (Sudhaik et al., 2018; Raizada et al., 2017a). Recently, nanostructured heterojunction which is formed between two or more semiconductor photocatalysts has got substantial attention. The heterojunction photocatalysts are utilized to enhance separation of photogenerated charge carriers, to tune the band gap and to make photocatalyst active over a wider spectrum for more effective photocatalytic oxidation reactions (Raizada et al., 2018b; Shandilya et al., 2018).

The carbonaceous substances like activated carbon, graphene, graphitic carbon nitride, carbon nanotubes, and CQD are environmentally and biologically viable materials as compared to inorganic compounds (Li et al., 2010; Raizada et al., 2017c). The carbon materials are used in the fabrication of nanocomposites as dispersants, adsorbents, and supports for expanding the surface area of photocatalysts (Das et al.,2018). The fluorescent-based quantum dots are generally of two kinds: graphene quantum dots (GQDs) and carbon quantum dots (CQDs) (Feng 
et al., 2018). CQDs are $\mathrm{sp}^{3}$ hybridized and amorphous whereas GQDs are $\mathrm{sp}^{2}$ hybridized and crystalline. The size of CQDs is less than $10 \mathrm{~nm}$ and fluorescence is due to surface defects. The size of GQDs is $2-20 \mathrm{~nm}$ and their fluorescence is due to quantum confinement (Zhu et al., 2013). Carbon quantum dots (CQDs) are of exclusive interest as an innovative family of materials for semiconductor photocatalysis (Yu et al., 2014; Wang et al., 2013). CQDs are fabricated using carbonization and oxidation, microwave method, electrochemical routes and hydrothermal methods (Barati et al., 2015). The precursors such as citric acid, candle soot, lampblack, glucose, papaya, tulsi leaves, grass, sweet red pepper, watermelon peels, garlic, chitin, chitosan, starch, cashew gum, lotus root, pomelo peel, potato, dextrin, glycine, rice flour, etc. have been used for CQDs fabrication (Liu et al., 2013a; Chen et al., 2013). The benefits of using natural resources for synthesis of CQDs are eco-friendly and cheap. The green synthesis methods are highly acceptable than chemical and physical methods. The researchers are encouraged to develop various new routes using naturally available carbon sources (Zhang et al., 2018a; Singh et al., 2013b).

In order to study historical and present trends of researches on carbon quantum dotsmodified supported photocatalysts for effective degradation of organic pollutants, a bibliometric scrutiny has been carried out using 'Scopus' database. Bibliometric study is an effectual method for assessing quantitative trends and historical development of research publications in a listed topic. (Ani et al., 2018). As per Scopus data, 1335 research articles were keyword "CQDs and photocatalyst" (Fig. 1a). On average, 135 research articles have been published per year. The most accessed articles are published in Journal of Cleaner Production, Journal of Photochemistry and Photobiology C: Photochemistry Reviews, Advances in Colloid and Interface Science, Nano today, Applied Catalysis B: Environmental, due to their significance to selected topic and details 
in their articles (Mallakpour et al., 2018). Most of the reviews on carbon quantum dots summarize their synthesis from various precursors, characterization and various applications such as solar water splitting, $\mathrm{CO}_{2}$ conversion, bio-imaging, targeted drug delivery, catalysis and solar cells (Fig. 1b). This review considered the use of CQDs modified semiconductor photocatalysts for the degradation of various organic pollutants, mechanism behind the designing of an effective photocatalyst, generation and transfer of charge carriers in modified photocatalyst and current findings on photostability and recyclability of CQDs modified photocatalysts.

\section{$<$ Please insert Fig. 1 here $>$}

\section{Mechanism of reaction between aqueous phase pollutants and semiconductor photocatalyst}

In photocatalytic reactions, upon light irradiation and activation of semiconductors, $\mathrm{e}^{-} / \mathrm{h}^{+}$ pairs formed through migration of photo-generated electrons from valence band (VB) to conduction band (CB) (Raizada et al., 2017b; Raizada et al., 2019b). The photogenerated $\mathrm{e}^{-} / \mathrm{h}^{+}$ pairs imitate oxidation and reduction reactions on the surface of photocatalyst, producing reactive oxygen species (ROS) like superoxide and hydroxyl radicals (Banerjee et al., 2005; Shandilya et al., 2019). The formed radicals interact with molecular structures of contaminants which decompose into less hazardous materials. There are several publications focusing on basic degradation mechanism of organic chemicals in the photocatalysis process (Fig. 2a) (Raizada et al., 2014b). The photocatalytic mechanism is explained by the following equations (Eqs. (1) (20)). The band end positions and redox potential of semiconductor photocatalysts in water $(\mathrm{pH}$ 7) are helpful to enhance the reaction selectivity of the reactant without negating the conversion (Fig. 2b). For photocatalytic degradation, reactive oxidative species are generated from reduction of $\mathrm{O}_{2}$ driven by photo-induced electrons in the $\mathrm{CB}$ of $\mathrm{OH}$ radicals and formation of $\mathrm{OH}$ radicals 
by photo-induced holes with strong oxidation capacity.

$A O P^{\prime} \mathrm{S}+\mathrm{OH} \cdot \rightarrow$ Pollutant molecule $\rightarrow \mathrm{CO}_{2}+\mathrm{H}_{2} \mathrm{O}+$ Inorganic ions

Pathway of charge separation for ROS production:

Photocatalyst $+h v \rightarrow e^{-}($conduction band $)+h^{+}($valence band $)$

$\mathrm{O}_{2}+e^{-} \rightarrow \mathrm{O}_{2} \quad E_{0}^{\prime}=-0.33 \mathrm{~V}$

$\mathrm{HO}_{2} \rightarrow \mathrm{O}_{2}^{\circ} \quad p K_{a}=4.8$

$\mathrm{O}_{2}+2 \mathrm{H}^{+}+e^{-} \rightarrow \mathrm{H}_{2} \mathrm{O}_{2} \quad E_{0}{ }^{\prime}=0.89 \mathrm{~V}$

$\mathrm{H}_{2} \mathrm{O}_{2} \rightarrow \mathrm{HO}_{2}^{-}+\mathrm{H}^{+} \quad p K_{a}=11.7$

$\mathrm{O}_{2}+2 \mathrm{H}^{+}+2 e^{-} \rightarrow \mathrm{H}_{2} \mathrm{O}_{2} \quad E_{0}{ }^{\prime}=0.28 \mathrm{~V}$

$\mathrm{H}_{2} \mathrm{O}_{2}+e^{-} \rightarrow \mathrm{OH}^{-}+\mathrm{OH}^{\cdot} \quad E_{0}{ }^{\prime}=0.38 \mathrm{~V}$

$\mathrm{H}_{2} \mathrm{O}+\mathrm{h}^{+} \rightarrow \mathrm{OH}+\mathrm{H}^{+} \quad{E_{0}}^{\prime}=2.32 \mathrm{~V}$

$O H^{\cdot} \rightarrow O_{2}^{-}+H^{+} \quad p K_{a}=11.8$

$2 \mathrm{HO}_{2}{ }^{1} \mathrm{O}_{2} \rightarrow \mathrm{H}_{2} \mathrm{O}_{2}$

$\mathrm{O}_{2}^{-}+h^{+} \rightarrow{ }^{1} \mathrm{O}_{2} \quad E_{0}{ }^{\prime}=0.65 \mathrm{~V}$

Interaction between radicals:

$2 \mathrm{HO}_{2} \rightarrow \mathrm{H}_{2} \mathrm{O}_{2}+\mathrm{O}_{2}$ 


$$
\begin{aligned}
& 2 \mathrm{HO}_{2}+\mathrm{O}_{2}^{--}+\mathrm{H}_{2} \mathrm{O} \rightarrow \mathrm{H}_{2} \mathrm{O}_{2}+\mathrm{O}_{2}+\mathrm{OH}^{-} \\
& 2 \mathrm{HO}_{2}^{\cdot} \rightarrow \mathrm{H}_{2} \mathrm{O}_{2} \\
& \mathrm{H}_{2} \mathrm{O}_{2}+\mathrm{hv}(\mathrm{UV}) \rightarrow 2 \mathrm{OH}^{-} \\
& \mathrm{H}_{2} \mathrm{O}_{2}+\mathrm{O}_{2}^{-\cdot} \rightarrow \mathrm{OH}^{-}+\mathrm{O}_{2}+\mathrm{OH}^{-} \\
& 3 \mathrm{O}_{2} \rightarrow \text { Photocatalyst intersystem crossing } \rightarrow{ }^{1} \mathrm{O}_{2}
\end{aligned}
$$

\section{Overall photocatalytic oxidation:}

$$
\text { ROS, } h^{+}+\text {contaminants } \rightarrow \text { oxidised products }\left(\mathrm{H}_{2} \mathrm{O}, \mathrm{CO}_{2}\right)
$$

$\mathrm{O}_{2}+$ contaminants $+\mathrm{hv} \rightarrow$ Photocatalyst $\rightarrow$ oxidized products $\left(\mathrm{H}_{2} \mathrm{O}, \mathrm{CO}_{2}\right)$

\section{Recombination of electron and hole pairs:}

$$
e^{-}+h^{+} \rightarrow \text { Heat }+\quad \text { Radiation less decay }
$$

Recombination of photogenerated electrons and holes is a major limitation that reduces the

overall efficiency of photocatalyst process. When recombination occurs, the photogenerated electrons tend to return back to valance band (VB) with the dissipation of energy as heat or light. The narrow band gap photocatalysts suffer more from recombination of photogenerated electron/hole $\left(\mathrm{e}^{-} / \mathrm{h}^{+}\right)$pairs. While wide band photocatalysts are mostly active in UV light. So, these contradictory factors must be balanced for the fabrication of efficient photocatalytic systems for water purification (Sudhaik et al., 2018).

\section{< Please insert Fig. 2 here $>$}

\section{Carbon quantum dots (CQDs) as potential photocatalytic material}


CQDs are a new family of fluorescence carbon nanoparticles, firstly fabricated by $\mathrm{Xu}$ and co-workers in 2004 by accident and reported as side products in arc discharged soot generation in the synthesis of carbon nano-tubes (Namdari et al., 2017). CQDs comprise of distinct quasi-spherical nanoparticles with a 10-nm particle size (Chan et al., 2002; Wang et al., 2010). They are valuable materials due to small particle size, fine biocompatibility, low cost, abundant surface functional groups, chemical inertness, low toxicity, broad varying optical properties, and tunable PL behavior (Yang et al., 2011; Xu et al., 2004). CQDs have found applications in bio-imaging (Gao et al., 2004), electrocatalysis, light emitting diodes, nanomedicines, bio-sensing, photodegradation, water mitigation, disease detection, drug/gene delivery, etc. (Zhou et al., 2017). Mostly, CQDs possess a graphitic $\mathrm{sp}^{2}$ core surrounded by $\mathrm{sp}^{3}$ carbons which have various functional groups including $\mathrm{C}-\mathrm{O}, \mathrm{C}-\mathrm{O}-\mathrm{C}, \mathrm{C}=\mathrm{O}, \mathrm{O}=\mathrm{C}-\mathrm{OH}$, etc. (Zuo et al., 2016). They manifest exceptional optical absorption in UV and visible region and have extraordinary modification capability to alter low energy photons into high energy photons and are utilized as a spectral converter for using full spectra of sunlight (Chan et al., 2002; Zhu et al., 2013). The various roles of CQDs in efficient photocatalysis can be classified as:

1) Acceptor and mediator for conduction band (CB) photogenerated electrons.

2) Improving visible light activity of wide band gap photocatalyst through photosensitization processes.

3) Reducing agent during the formation of various metal nanoparticles with surface plasmon resonance (SPR) phenomenon.

4) Efficient harvesting of wide solar spectrum via up-conversion photoluminescence (UCPL) phenomenon involving the emission of shorter wavelength light than used for excitation of CQDs. 
5) Enhanced adsorption of pollutants onto photocatalyst surface.

Moreover, to clarify the complicated optical nature of CQDs, several justifications have been given such as quantum confinement effect (Fig. 3a) (Barman et al., 2018), surface defect and $\pi$-conjugation. The up-conversion PL activity of CQDs can magnify the range of light exploitation of nanomaterials from UV to visible range and boost the transfer of electrons (Ding et al., 2016). The level of oxidation of surface state has a critical role in tunable light emission (Fig. 3b) (Reshma et al., 2018). CQDs can replace usual photosensitizers (noble metals, organic dyes, and metal sulphides) which have toxicity and environmental-unfriendly effects (Deifallah et al., 2008). For the fabrication of CQDs, top-down and bottom-up methods are generally used. The top-up approach uses macroscopic structures initially, which can be controlled externally in the fabrication of nanostructures. The bottom-up approach includes contraction of material components with further self-assembly practice leading to the foundation of nanostructures (Namdari et al., 2017). These approaches can be understood through chemical synthesis and physical synthesis. Top-down approaches involve electrochemical oxidation, arc-discharge, ultrasonic synthesis, laser ablation and chemical oxidation which employ macroscopic carbon sources, whereas bottom-up approaches include template-based chemistry, microwave synthesis, hydrothermal treatment and thermal decomposition (Fig. 4). Li and co-workers used graphite rods as both cathode and anode for fabrication of CQDs of size 1- $4 \mathrm{~nm}$ via an alkali-assisted electrochemical procedure and exhibited enhanced up-converted PL characteristics which were size-dependent ( $\mathrm{Li}$ et al., 2010b). In other reported work, biochar has been employed for fabrication of CQDs as photocatalyst via reflux, annealing, dialysis and centrifugation treatments. The acid-assisted splitting procedure is a general route for fabrication of CQDs modified photocatalyst composites from various precursors such as soot, carbon powders, etc. 
(Zhang et al., 2013; Qu et al., 2013). CQDs can be employed in the process of photocatalysis as photosensitizers and electron reservoirs. The fabrication of N-CQDs via an ultrasonic process with glucose and solution of $\mathrm{NH}_{4} \mathrm{OH}$ as beginning ingredients was reported by $\mathrm{Ma}$ and coworkers (Ma et al., 2012). $\mathrm{Cu}-\mathrm{N}-\mathrm{CQD}$ s was synthesized using $\mathrm{Na}_{2}[\mathrm{Cu}(\mathrm{EDTA})]$ as a precursor at $250{ }^{\circ} \mathrm{C}$ and temperature played a vital role in the production of $\mathrm{Cu}-\mathrm{N}-\mathrm{CQDs}$. During pyrolysis, the assembly was converted into a copper-coordinated complex chelated with graphene matrix (Wu et al., 2015). Since the photocatalytic mechanism of CQDs modified photocatalyst composite needs to be entirely explored, several types of mechanisms have been suggested by researchers working in the field (Li et al., 2014). The aromatic rings of CQDs form $\pi$ - $\pi$ stacking with organic contaminants having aromatic rings, therefore enhancing the adsorption of organic pollutants. Furthermore, the existence of functional groups such as carbonyl, hydroxyl, epoxy, and amino groups on the surface of CQDs can interact with several of molecules and metal ions, leading to enhanced adsorption (Namdari et al., 2017).

\section{< Please insert Fig. 3 and 4 here>}

\section{Rational designing of CQD supported photocatalysts}

Because of outstanding charge carrier transfer, photosensitization and up-converted PL (UPCL) effect, CQDs have been utilized for modification of photocatalyst composite to raise their photocatalytic activity (Bajorowicz et al., 2018; Yu et al., 2007). After commencement of CQDs, expanded the range of photo responding and organized charge separation leads to enhancement in photocatalytic activity (Wang et al., 2010). The mechanism of excitation and photoactivity of CQDs modified photocatalysts are fully depended on band gap, valence band, and conduction band. The main cases can be categorized as follows. 
1. CQDs modified wide band gap photocatalysts $\left(\mathrm{E}_{\mathrm{g}} \geq 3 \mathrm{eV}\right)$.

2. CQDs modified narrow band gap photocatalysts $\left(\mathrm{E}_{\mathrm{g}} \leq 3 \mathrm{eV}\right)$.

3. CQDs modified Z-scheme semiconductor photocatalysts.

The mechanism of excitation of CQDs modified narrow band gap semiconductor photocatalysts can be categorized into two forms on the basis of source of irradiations used for activation of photocatalysts. Under UV light, CQDs acts as an electron reservoir for trapping conduction band electrons released from photocatalysts, decreasing the efficiency of the $\mathrm{e}^{-} / \mathrm{h}^{+}$ recombination process (Fig. 5a). In case of NIR-visible radiations, CQDs display upconversion photoluminescence phenomenon (UCPL) which means that they can act as absorber of longer wavelength lights in the near-infrared or visible region and emit smaller wavelength light via up-conversion route and, in turn can stimulate photocatalyst particles to form $\mathrm{e}^{-} / \mathrm{h}^{+}$pairs (Fig. 5b). At the same time, CQDs also acts as an electron acceptor for conduction band electrons of narrow band gap photocatalyst (Fig. 5c). In presence of visible light, CQD accepts photogenerated electrons from the conduction band of narrow band photocatalyst. Under NIRvisible light irradiations, photocatalytic activity enhances due to up-conversion photoluminescence phenomenon and electron sink behavior of CQDs for photogenerated electrons at conduction band (Fig. 5d) (Bajorowicz et al., 2018).

\section{$<$ Please insert Fig. 5 here >}

Among various semiconductor heterojunctions, type-II and Z-scheme heterojunction formation is a facile way for enhancing photocatalytic activity of semiconductor photocatalyst (Maeda, 2013). In type II heterojunction, both valance and conduction band of semiconductor photocatalysts (SC I) are higher than semiconductor photocatalysts (SC II). So photogenerated 
electrons at conduction band SC I will migrate towards conduction band SC II, while valance band holes of SC II will transfer to SC I. It results in effective separation of photogenerated electron pairs. The oxidation reactions of type-II heterojunction photocatalysts occur with lower oxidation potential SC I as compared to SC II and overall oxidative efficiency was significantly reduced. In addition, due to hole-hole and electron-electron repulsion, the movement of electron and holes was restricted. In view of above-discussed drawbacks of the type-II photocatalyst, Zscheme heterojunctions are regarded as an effective strategy to form efficient photocatalytic system (Low et al., 2017).

In the Z-scheme mechanism (Fig. 6), photoexcited electrons in conduction band of SC I transfer to valence band of SC II (Wang et al., 2016). This leads to separation of electrons in conduction band of CQDs with photoexcited holes in valence band of photocatalyst particles holes accumulated in valence band of CQDs. The electrons accumulated in conduction band of photocatalyst nanoparticles involve oxidation and reduction reactions. Such a heterojunction facilitates semiconductor photocatalysts with narrow gaps without losing any robust redox potential of photo-induced electrons and holes ( $\mathrm{Li}$ et al., 2016). The first generation Z-scheme photocatalysts involves the use liquid phase redox ion pairs such as $\mathrm{I}^{-} / \mathrm{IO}_{3}{ }^{-}, \mathrm{Fe}^{2+} / \mathrm{Fe}^{3+}$ as electron mediators or transfer of photoexcited electrons in conduction band of SC I transfer to valence band of SC II. However, in these processes, donor $\left(\mathrm{Fe}^{3+}\right)$ and accepter $\left(\mathrm{Fe}^{2+}\right)$ compete with aqueous phase pollutant molecules for reduction and oxidation reaction, respectively in photocatalytic reaction. Therefore, photo-conversion efficiency of liquid phase mediators supported Z-scheme photocatalytic system will be severely decreased. The redox capability of photocatalytic system is compromised due to the fact that reduction and oxidation processes arise on semiconductor with lesser reduction and oxidation potentials, respectively. Light scattering 
effect, slow electron hole-pair transfer due to the diffusion of ion pairs, and $\mathrm{pH}$ sensitivity also restrict the applicability of liquid phase mediators in Z-scheme photocatalysis. Moreover, the recovery of liquid phase redox ion pair mediator remains as another important issue for large scale application of theses photocatalytic systems (Shi et al., 2017). In order to make practical utility of Z-scheme photocatalysts, use of noble metals ( $\mathrm{Au}, \mathrm{Ag}$, and $\mathrm{Cu}$ NPs) as solid-state electron mediators is preferred to facilitate charge carrier separation. However, high cost and rarity of noble metals severely limit their wide application in the Z-scheme photocatalytic system. Secondly, owing to the strong light absorption ability of noble metals, the lightabsorption ability of the photocatalyst is greatly reduced by their presence in Z-scheme photocatalyst via shielding mechanism (Zheng et al., 2009). The low cost and facile synthesis methods are the main advantages of CQDs over noble metals. CQDs can facilitate Z-scheme process by acting as a mediator for transfer photo-generated conduction band electrons of SC I to valence band of SC II (Zhou et al., 2014).

\section{< Please insert Fig. 6 here>}

\section{CQDs modified wide band gap photocatalysts $\left(E_{g} \geq 3 \mathrm{eV}\right)$.}

Wide band gap semiconductor such as $\mathrm{TiO}_{2}, \mathrm{ZnO}, \mathrm{BiOBr}$, etc. has been acknowledged as an excellent material for photocatalysis because of their large band gap, non-toxic nature, high photosensitivity, photochemical stability and low cost (Yu et al., 2012; Wang et al., 2010). Also, wide band gap of $\mathrm{TiO}_{2}$ can only exploit from UV light of sunlight, which forms only a minor fraction of the whole solar spectra reaching the earth surface (Smith et al., 2009; Chai et al., 2018). Due to this their application range is restricted. Nevertheless, $\mathrm{ZnO}$ shows poor quantum efficiency which limits its industrial applications (Pare et al., 2008a; Rakshit et al., 2012). Therefore, various methods have been reported to enhance the quantum efficiency of 
photocatalyst by modifying it with carbon based nano-materials (Aryal et al., 2008; Zhao et al., 2013). The modification of wide band gap photocatalyst with CQDs improves charge separation and reduces charge recombination and, hence, enhance photocatalytic activity (Raizada et al., 2016b; Wang et al., 2016).

In a reported work, Miao and co-workers demonstrated the fabrication of CQDs decorated porous $\mathrm{TiO}_{2}$ photocatalyst for removal of methylene blue (MB) and N-benzylideneaniline (NB) via sol-gel and ultrasonic-hydrothermal methods under visible light irradiation (Miao et al., 2016). CQDs $/ \mathrm{TiO}_{2}$ photocatalyst degraded $98 \%$ of $\mathrm{MB}$ in $1 \mathrm{~h}$ and $30 \%$ of $\mathrm{NB}$ in $2 \mathrm{~h}$ which was higher than pristine meso-Ti-450 and CQDs. The presence of $\mathrm{O}_{2}$ containing groups and aromatic rings of CQDs contributed adsorption towards the MB and N-benzylideneaniline molecules on photocatalyst composite. CQDs absorbed longer wavelength light (> $600 \mathrm{~nm}$ ), emitted shorter wavelength light in UV light range and excited $\mathrm{TiO}_{2}$ to generate electrons and holes. The electron reservoir and up-conversion properties of CQDs facilitated exploitation of visible light and hindered recombination of $\mathrm{e}^{-} / \mathrm{h}^{+}$(Fig. 7a) (Miao et al., 2016). Ali and his co-workers reported the synthesis of $\mathrm{P} 25 / \mathrm{CQDs}$ photocatalyst for the removal of Rhodamine $\mathrm{B}(\mathrm{RhB})$, methyl orange (MO) and 4-chlorophenol (4CP) under visible light. The composite photocatalyst degraded $80 \%$ of RhB, $40 \%$ of $\mathrm{MO}$, and $49 \%$ of 4CP which were more than those of bare $\mathrm{P} 25$ (49\% of $\mathrm{RhB}, 33 \%$ of $\mathrm{MO}$ and $46 \%$ of $4 \mathrm{CP}$ ). It was also reported that the formation of $\mathrm{OH}$ radical played a vital role in the degradation of the dyes. Fig. $7 b$ depicts a mechanism for photocatalytic degradation of $\mathrm{RhB}, \mathrm{MO}$, and 4CP over P25/CQDs photocatalyst (Ali et al., 2019). Hydrothermal synthesis of CQDs modified $\mathrm{TiO}_{2}$ photocatalyst composites was reported using citric acid (CA) and glucose $(\mathrm{G})$ as precursors for degradation of pollutant phenol under UV light irradiation (Shen et al., 2018). CQDs modified $\mathrm{G} / \mathrm{TiO}_{2}$ photocatalyst showed $99 \%$ 
degradation ratio of phenol which was higher than that of $\mathrm{CQDs}$ modified $\mathrm{CA} / \mathrm{TiO}_{2}$ photocatalyst. The $\pi-\pi$ interaction of CQDs and phenol was beneficial to absorption of phenol on the surface of $\mathrm{CQDs} / \mathrm{TiO}_{2}$ photocatalyst. CQDs served as electron reservoirs and trapped photogenerated electrons from the conduction band of $\mathrm{TiO}_{2}(\mathrm{P} 25)$. Hence, CQDs accelerated the separation of $\mathrm{e}^{-}-\mathrm{h}^{+}$pairs and enhanced photocatalytic activity (Fig. 7c) (Shen et al., 2018).

\section{< Please insert Fig. 7 here $>$}

Li et al. synthesized CQDS modified ZnO photocatalysts via simple sol-gel methodology along with a spin-coating process for photodegradation of Rhodamine B (Li et al., 2013). CQDs modified $\mathrm{ZnO}$ photocatalyst with 4-layers showed 3 times more photocatalytic activity than bare $\mathrm{ZnO}$ due to electronic interaction between $\mathrm{CQDs}$ and $\mathrm{ZnO}$, increased separation of photogenerated charge and enhanced transfer of $\mathrm{e}^{-}-\mathrm{h}^{+}$pairs. The improved photocatalytic action was mainly due to electron reservoir and up-converted behavior of CQDs (Fig. 8a) (Li et al., 2013). Muthulingam and co-workers conveyed the preparation of CQDs decorated N-doped ZnO photocatalyst composites via single-step method for degradation of malachite green (MG), methylene blue (MB) and fluorescein dyes under daylight irradiation (Muthulingam et al., 2015). The degradation ratio of $\mathrm{MG}$ for CQDs/N-ZnO and N-ZnO photocatalyst was $100 \%$ and $60 \%$ respectively, after $30 \mathrm{~min}$. The degradation ratio of fluorescein dye over $\mathrm{CQDs} / \mathrm{N}-\mathrm{ZnO}$ photocatalyst was $100 \%$ after $30 \mathrm{~min}$ and over $\mathrm{N}-\mathrm{ZnO}$ photocatalyst was $92 \%$ after $60 \mathrm{~min}$. The wide range capability of photocatalyst facilitated higher charge efficiency, suppressed photocorrosion and led to better photocatalyst for wastewater treatment (Fig. 8b) (Muthulingam et al., 2015). Ding and co-workers fabricated CQDs modified $\mathrm{ZnO}$ foam composite for degradation of methylene blue (MB), methyl orange and Rhodamine $\mathrm{B}(\mathrm{Rh} \mathrm{B})$ under visible and UV irradiation (Ding et al., 2016). The value of $\mathrm{k}$ for MB, MO and RhB were 0.0121, 0.0031 
and $0.0092 \mathrm{~min}^{-1}$ respectively. The degradation of dyes was in order $\mathrm{MO}<\mathrm{RhB}<\mathrm{MB}$. Due to their up-conversion property, the CQDs improved the photocatalytic activity, as measured by excitation wavelengths 600 to $850 \mathrm{~nm}$. Also, CQDs acted as electron reservoir, photogenerated electrons were transferred from $\mathrm{ZnO}$ surface to CQDs and recombination of $\mathrm{e}^{-}-\mathrm{h}^{+}$pairs suppressed efficiently (Ding et al., 2016). Kaur and co-workers reported a facile procedure for fabrication of CQDs modified $\mathrm{ZnS}$ photocatalyst composites via precipitation scheme for the degradation of Alizarin Red S (ARS) dye under visible light (Kaur et al., 2016). The photocatalytic activity of CQDs/ZnS photocatalyst for degradation of ARS dye was $89 \%$ after 250 min that was higher than bare $\mathrm{ZnS}(63 \%)$. When CQDs was introduced to ZnS, electrons from conduction band (CB) of $\mathrm{ZnS}$ transferred to $\mathrm{CQDs}$ and resulted into an effective separation of $\mathrm{e}^{-}-\mathrm{h}^{+}$pairs. The photo-induced property of CQDs enhanced the photocatalytic activity, improved interfacial charge transfers and suppressed charge recombination (Fig. 8c) (Kaur et al., 2016).

CQDs decorated $\mathrm{BiOBr}$ photocatalyst composite was fabricated by Ji and his co-workers via hydrothermal route for degradation of Bisphenol A (BPA), Tetracycline (TC), and Rhodamine B (Rh B) under visible light (Ji et al., 2018). 3.1 wt \% CQDs/BiOBr photocatalyst showed the highest photocatalytic activity for TC degradation (60\%) after 120 min under visible light illumination. $91.8 \%$ of $\mathrm{Rh} \mathrm{B}$ was degraded by $3.1 \mathrm{wt} \% \mathrm{CQDs} / \mathrm{BiOBr}$ photocatalyst whereas only $22.7 \%$ of $\mathrm{Rh} \mathrm{B}$ was removed by bare $\mathrm{BiOBr}$ after 20 min. 3.1 wt \% CQDs/BiOBr photocatalyst degraded $73 \%$ of BPA after 150 min which was higher than that of bare $\mathrm{BiOBr}$. Photodegradation activity for resultant photocatalyst of $\mathrm{TC}$ and $\mathrm{Rh} \mathrm{B}$ was 4 times higher than that of pristine $\mathrm{BiOBr}$. The enhanced photocatalytic action is accredited to the synergetic effect between $\mathrm{BiOBr}$ and $\mathrm{CQDs}$. The $\mathrm{CQDs}$ acted as an electron reservoir to stimulate charge 
separation and transfer, suppressed recombination prospect and improved life span of $\mathrm{e}^{-}-\mathrm{h}^{+}$pairs (Ji et al., 2018). CQDs modified $\mathrm{KNbO}_{3}$ photocatalyst composite was fabricated via hydrothermal and mixed-calcination technique for the removal of crystal violet dye under visible light illumination (Qu et al., 2018b). $\mathrm{CQDs} / \mathrm{KNbO}_{3}$ photocatalyst with a mass ratio of 1.5:0.5 degraded $70 \%$ of crystal violet dye after $5 \mathrm{~h}$ whereas bare $\mathrm{KNbO}_{3}$ degraded only $41.5 \%$ of dye. Firstly, CQDs acted as up-conversion material and converted visible light to UV light due to excellent up-conversion behavior. Secondly, CQDs used as co-catalyst and formed more active sites on $\mathrm{KNbO}_{3}$ surface due to excellent electronic conductivity (Fig. 8d) (Qu et al., 2018b).

\section{< Please insert Fig. 8 here $>$}

\section{CQDs modified narrow band gap $\left(\mathbf{E}_{\mathrm{g}}<3\right)$ photocatalysts.}

Due to easy generation of electrons and holes and having extremely negative reduction potential, narrow band gap photocatalysts are noble photocatalytic material. However, their photocatalytic action is limited due to low light absorption efficiency, restricted migration and high recombination of electron and hole pairs. Thus, a suitable modification with carbon nanomaterials for these low band gap photocatalysts is essential. The modification of photocatalyst with CQDs hinder recombination of photogenerated electrons and holes and ultimately enhance photocatalytic activity. Liu and co-workers reported the fabrication of CQDs modified CdS (CQDs/CdS) photocatalyst composites via a hydrothermal process for the degradation of dye Rhodamine $\mathrm{B}$ ( $\mathrm{Rh} \mathrm{B})$ under visible light irradiation by varying concentration of CQDs in solutions containing glutathione (Liu et al., 2013b). The photo-degradation efficiency of Rh B for CQDs/CdS photocatalyst and bare CdS was $90 \%$ and $50 \%$ respectively after $1 \mathrm{~h}$ under visible light irradiation. The photocatalytic activity of CQDs/CdS was higher than that of bare CdS because CQDs trapped electrons and hindered recombination of generated $\mathrm{e}^{-}-\mathrm{h}^{+}$pairs. Also, 
up-converted property made resultant photocatalyst utilize visible light more effectively and hence, increased photocatalytic activity (Fig. 9a) (Liu et al., 2013b). In other studies, Sun et al. reported the fabrication of $\mathrm{CQDs}$ decorated $\mathrm{Bi}_{2} \mathrm{MoO}_{6}$ photocatalyst composite via a hydrothermal process for photodegradation of Rhodamine B (RhB) and Methylene Blue (MB) below visible light irradiation (Sun et al., 2017). (0.1g) CQDs/ $\mathrm{Bi}_{2} \mathrm{MoO}_{6}$ photocatalyst composite degraded $100 \%$ of $\mathrm{MB}$ whereas bare $\mathrm{Bi}_{2} \mathrm{MoO}_{6}$ removed only $91 \%$ of $\mathrm{MB}$ after 120 min under visible light irradiation. Also, $100 \%$ and $85 \%$ of $\mathrm{Rh} \mathrm{B}$ was degraded by $(0.1 \mathrm{~g}) \mathrm{CQDs} / \mathrm{Bi}_{2} \mathrm{MoO}_{6}$ photocatalyst composite and bare $\mathrm{Bi}_{2} \mathrm{MoO}_{6}$ after 120 min under visible light irradiation. It was stated that electron was excited from VB to $\mathrm{CB}$ by high energy photon and electrons in $\mathrm{Bi}_{2} \mathrm{MoO}_{6}$ transferred to CQDs quickly due to their outstanding electric conductivity. The enhanced photocatalytic activity of resultant photocatalyst was attributed to the formation of a junction interface between $\mathrm{Bi}_{2} \mathrm{MoO}_{6}$ and CQDs which inhibited recombination of charge carriers (Fig. 9b) (Sun et al., 2017). CQDs modified $\mathrm{Fe}_{3} \mathrm{O}_{4}$ photocatalyst composite was fabricated by Wang et al. via the solvothermal method for the degradation of Methylene blue (MB) under visible light irradiation (Wang et al., 2014). (6.0) $\mathrm{CQDs} / \mathrm{Fe}_{3} \mathrm{O}_{4}$ photocatalyst degraded $100 \%$ of MB after 15 min under visible light irradiation. The highly fluorescent CQDs assembled on $\mathrm{Fe}_{3} \mathrm{O}_{4}$ surface that was essential for excellent optical properties and enhanced photocatalytic action. Up-conversion behavior of CQDs, production of more $\mathrm{e}^{-}-\mathrm{h}^{+}$pairs directed to increased photocatalytic performance of $\mathrm{CQDs} / \mathrm{Fe}_{3} \mathrm{O}_{4}$ photocatalyst (Wang et al., 2014). Di et al. fabricated CQDs modified $\mathrm{Bi}_{2} \mathrm{WO}_{6}$ photocatalyst composites via the hydrothermal method for degradation of Rhodamine B (Rh B), bisphenol A (BPA), tetracycline hydrochloride (TC), and ciprofloxacin (CIP) under visible light (Di et al., 2015). CQDs/ $\mathrm{Bi}_{2} \mathrm{WO}_{6}$ degraded $87 \%$ of CIP after 120 min. $\mathrm{CQDs} / \mathrm{Bi}_{2} \mathrm{WO}_{6}$ showed 1.8 times more degradation rate for removal of $\mathrm{Rh} \mathrm{B}$ than bare $\mathrm{Bi}_{2} \mathrm{WO}_{6}$ 
after 30 min under visible light irradiation. Results disclosed that $\mathrm{CQDs} / \mathrm{Bi}_{2} \mathrm{WO}_{6}$ showed the highest photocatalytic activity than bare $\mathrm{Bi}_{2} \mathrm{WO}_{6}$ for degradation of $\mathrm{TC}$ and $\mathrm{BPA}$. When $\mathrm{Bi}_{2} \mathrm{WO}_{6}$ contacted with CQDs to form composite, photogenerated electrons on $\mathrm{CB}$ of $\mathrm{Bi}_{2} \mathrm{WO}_{6}$ transferred to CQDs and CQDs initiated $\mathrm{e}^{-}-\mathrm{h}^{+}$pairs separation. Due to electron reservoir and up-converted behavior of CQDs, the photocatalytic performance of photocatalyst enhanced (Fig. 9c) (Di et al., 2015). CQDs modified $\mathrm{Cu}_{2} \mathrm{O}$ photocatalyst composite was fabricated for the degradation of methylene blue (MB) under near-infrared light illumination (Li et al., 2012). The amount of CQDs in photocatalyst affected photocatalytic action of $\mathrm{CQDs} / \mathrm{Cu}_{2} \mathrm{O}$ photocatalyst. $90 \%$ of $\mathrm{MB}$ was degraded by $(7.16 \mathrm{wt} \%) \mathrm{CQDs} / \mathrm{Cu}_{2} \mathrm{O}$ photocatalyst and when the content of CQDs increased, the degradation rate for MB decreased to $88 \%$. This happened due to an extra amount of CQDs which blocked $\mathrm{e}^{-}-\mathrm{h}^{+}$pairs from reacting with $\mathrm{O}_{2} / \mathrm{OH}^{-}$usually and produced active oxygen radicals $\left(\mathrm{O}_{2}, \mathrm{OH}\right)$. The resultant photocatalyst showed excellent photocatalytic activity due to the combined effect of light reflecting the capacity of $\mathrm{Cu}_{2} \mathrm{O}$ and up-converted PL behavior of CQDs (Li et al., 2012).

\section{$<$ Please insert Fig. 9 here $>$}

\section{CQDs modified heterojunction photocatalysts}

Solvothermal synthesis of a $\mathrm{CQD}$ modified $\mathrm{BiOCl} / \mathrm{BiOBr}$ heterojunction for the degradation of organic pollutants bisphenol A (BPA), rhodamine B (Rh B), ciprofloxacin (CIP), and tetracycline hydrochloride (TC) under visible light irradiation was reported (Hu et al., 2018). $5 \%$ wt. of $\mathrm{CQDs} / \mathrm{BiOCl} / \mathrm{BiOBr}$ displayed maximum photocatalytic action for degradation of $\mathrm{RhB}, \mathrm{TC}, \mathrm{CIP}$ and $\mathrm{BPA}$ that was 2.1, 2.8, 3.0 times more than that of $\mathrm{BiOCl} / \mathrm{BiOBr}, \mathrm{BiOBr}$, $\mathrm{BiOCl}$ respectively. After the introduction of CQDs, excited electrons on $\mathrm{CB}$ of $\mathrm{BiOCl} / \mathrm{BiOBr}$ transferred to CQDs which resulted into a high separation of $\mathrm{e}^{-}-\mathrm{h}^{+}$pairs. Thus, enhanced 
photocatalytic activity was due to photocurrent analysis, up-converted PL and electron reservoir behavior. The photocatalytic and charge transfer mechanism of resultant heterojunction is discussed in Fig. 10a (Hu et al., 2018). Pan et al. stated synthesis of Z-scheme CQDs modified $\mathrm{CdS} / \mathrm{BiOCl}$ heterojunction via region-selective deposition route for degradation of phenol and Rhodamine B (Rh B) under visible light (Pan et al., 2018). The bare BiOCl degraded only $42 \%$ of phenol after $2 \mathrm{~h}$ and CQDs/CdS/BiOCl heterojunction degraded $99.5 \%$ of phenol within 105 min under UV light illumination. The degradation rate constant for synthesized heterojunction for degradation of $\mathrm{Rh} \mathrm{B}$ and phenol was $0.056 \mathrm{~cm}^{-1}$ and $0.0385 \mathrm{~cm}^{-1}$ respectively. CQDs transferred the photogenerated electrons in $\mathrm{CB}$ of $\mathrm{BiOCl}$ to $\mathrm{VB}$ of $\mathrm{CdS}$ which improved photogenerated $\mathrm{e}^{-}-\mathrm{h}^{+}$pairs separation and performance of optical absorption of BiOCl under visible light. The above photocatalytic action of heterojunction attributed to exceptional redox ability in Z-scheme system and Fig. 10b illustrated charge transfer in CQDs/CdS/BiOCl heterojunction (Pan et al., 2018). $\mathrm{TiO}_{2} / \mathrm{BiOI} / \mathrm{CQDs}$ (TBC) heterojunction was fabricated by $\mathrm{Qu}$ et al. for degradation of methyl orange (MO) under visible light (Qu et al., 2018a). It was also stated that TBC heterojunction exhibited the highest kinetic apparent rate constant $\left(\mathrm{k}_{\mathrm{app}}\right)(90 \%)$ for degradation of $\mathrm{MO}$ dye. TBC heterojunction showed 2 times more photocatalytic activity for removal of $\mathrm{MO}$ than of $\mathrm{TiO}_{2} / \mathrm{BiOI}, \mathrm{TiO}_{2} / \mathrm{CQDs}$ and $\mathrm{TiO}_{2}$. $\mathrm{TBC}$ heterojunction showed excellent photocatalytic activity due to the synergetic effect between CQDs and BiOI. CQDs acted as electron reservoir, led to fast transfer and low recombination of photogenerated $\mathrm{e}^{-}-\mathrm{h}^{+}$pairs. The photocatalytic mechanism of TBC heterojunction is explained in Fig. 10c (Qu et al., 2018a). Chen et al. reported the fabrication of CQDs modified $\mathrm{Ag} / \mathrm{Ag}_{2} \mathrm{O}$ heterojunction for degradation of Rhodamine B (Rh B) and Methylene blue (MB) under UV light irradiation (Chen et al., 2016). The photodegradation efficacy of $\mathrm{MB}$ over $\mathrm{CQD} / \mathrm{Ag} / \mathrm{Ag}_{2} \mathrm{O}$ heterojunction was $95 \%$ after 80 min 
which was superior to $\mathrm{CQDs} / \mathrm{Ag}_{2} \mathrm{O}(82 \%), \mathrm{Ag} / \mathrm{Ag}_{2} \mathrm{O}(63 \%)$ and $\mathrm{Ag}_{2} \mathrm{O}(45 \%)$ after 60 min under UV radiation. The photodegradation rate of $\mathrm{RhB}$ over resultant heterojunction was $48 \%$ after 150 min under $\mathrm{N}(\mathrm{IR})$ illumination. No or low degradation of $\mathrm{RhB}$ was observed for $\mathrm{CQDs} / \mathrm{Ag}_{2} \mathrm{O}, \mathrm{Ag} / \mathrm{Ag}_{2} \mathrm{O}$, and $\mathrm{Ag}_{2} \mathrm{O}$. The enhanced photocatalytic activity was attributed to SPR effect, electron reservoir and up-converted PL properties of CQDs. The heterojunction provided electron pathway, $\mathrm{Ag}_{2} \mathrm{O} \rightarrow \mathrm{CQDs} \rightarrow$ Ag for effective $\mathrm{e}^{-}-\mathrm{h}^{+}$pairs separation (Fig. 10d) (Chen et al., 2016).

\section{< Please insert Fig. 10 here $>$}

Zhang and co-workers prepared CQDs/Ag/ $\mathrm{Bi}_{2} \mathrm{O}_{2} \mathrm{CO}_{3}$ heterojunction for removal of Methylene blue (MB) and Bisphenol A (BPA) under solar, UV, visible light irradiation. 3$\mathrm{CQDs} / \mathrm{Ag} / \mathrm{Bi}_{2} \mathrm{O}_{2} \mathrm{CO}_{3}$ heterojunction degraded 93.85 and $54.88 \%$ of $\mathrm{MB}$ and $\mathrm{BPA}$ respectively, under visible light irradiation (Zhang et al., 2019). Also, 3-CQDs/Ag/ $\mathrm{Bi}_{2} \mathrm{O}_{2} \mathrm{CO}_{3}$ heterojunction degraded $73.75 \%$ of $\mathrm{MB}$ under UV light irradiation and $99.25 \%$ of MB under solar light irradiation. The synergetic effect of up-conversion behavior of CQDs and surface plasmon resonance (SPR) from $\mathrm{Ag}$ improved full spectra absorption, charge transfer for $\mathrm{CQDs} / \mathrm{Ag} / \mathrm{Bi}_{2} \mathrm{O}_{2} \mathrm{CO}_{3}$ heterojunction in wastewater treatment and enhanced photocatalytic action of CQDs modified $\mathrm{Ag} / \mathrm{Bi}_{2} \mathrm{O}_{2} \mathrm{CO}_{3}$ heterojunction under solar light (Fig. 11a) (Zhang et al., 2019). $\mathrm{Li}$ and co-workers reported the fabrication of $\mathrm{CQDs}$ modified $\mathrm{Bi} / \mathrm{BiOCl} / \mathrm{TiO}_{2}$ heterojunction via solvothermal method followed by a hydrothermal process for removal of methyl orange (MO) and p-nitrophenol (PNP) under visible light irradiation (Li et al., 2018). About $82 \%$ of PNP was degraded after $240 \mathrm{~min}$ by $\mathrm{CQDs} / \mathrm{Bi} / \mathrm{BiOCl} / \mathrm{TiO}_{2}$ which was 10.3 times more than that of $\mathrm{BiOCl} / \mathrm{TiO}_{2}$. Also, $94 \%$ of $\mathrm{MO}$ was degraded after $100 \mathrm{~min}$ by $\mathrm{CQDs} / \mathrm{Bi} / \mathrm{BiOCl} / \mathrm{TiO}{ }_{2}$ which was 4.8 times more than that of $\mathrm{BiOCl} / \mathrm{TiO}_{2}$. $\mathrm{CQDs}$ and $\mathrm{Bi}$ co-catalyst served as electron donors, 
$\mathrm{TiO}_{2}$ and $\mathrm{BiOCl}$ acted as electron trappers to increase the lifetime of photogenerated $\mathrm{e}^{-}-\mathrm{h}^{+}$pairs. The up-conversion and electron reservoir properties of CQDs, SPR effect of Bi co-catalyst played an important role in enhanced photocatalytic action of heterojunction (Fig. 11b) (Li et al., 2018). CQDs modified TNTs heterojunction were fabricated via the hydrothermal method for photodegradation of Methylene blue (MB) under visible light irradiation (Zhao et al., 2018). CQDs/TNTs showed the highest photocatalytic activity and degraded $91.3 \%$ of MB after 50 min under visible light illumination that was 2 times more than that of bare TNTs. CQDs with excellent up-conversion property converted longer wavelength light (>600 nm) into shorter wavelength light $(<600 \mathrm{~nm})$ and hence, activated TNTs to generate $\mathrm{e}^{-}-\mathrm{h}^{+}$pairs. CQDs captured the generated $\mathrm{e}^{-} \mathrm{h}^{+}$pairs and increased their lifetime. The $\pi-\pi$ interaction between CQDs and benzene resulted in enhanced absorption performance of CQDs/TNTs photocatalysts (Fig. 11c) (Zhao et al., 2018). CQDs modified hydrogenated $\mathrm{TiO}_{2}$ nanobelt heterojunction were fabricated by Tian et al. for removal of Methyl orange (MO) under UV irradiation, visible irradiation and Near Infrared Radiation (NIR) (Tian et al., 2015). CQDs/ $\mathrm{H}-\mathrm{TiO}_{2}$ degraded more than $86 \%$ of MO within 225 min under UV light illumination which was higher than that of P25 and bare $\mathrm{TiO}_{2}$ nanobelts. Under visible light irradiation, $\mathrm{CQDs} / \mathrm{H}-\mathrm{TiO}_{2}$ degraded $50 \%, \mathrm{H}-\mathrm{TiO}_{2}$ nanobelts $45 \%, \mathrm{P} 2526 \%$ and bare $\mathrm{TiO}_{2} 17 \%$ of $\mathrm{MO}$ within 25 min. Also under NIR light irradiation, $\mathrm{CQDs} / \mathrm{H}-\mathrm{TiO}_{2}$ heterojunction degraded $32 \%$ of $\mathrm{MO}$ after 120 min whereas $\mathrm{H}-\mathrm{TiO}_{2}$ nanobelts, P25 and bare $\mathrm{TiO}_{2}$ showed no or less degradation of $\mathrm{MO}$. When CQDs introduced to $\mathrm{H}-\mathrm{TiO}_{2}$ belt, photocatalytic activity of heterojunction was enhanced by promoting separation of photogenerated $\mathrm{e}^{-}-\mathrm{h}^{+}$pairs due to electron reservoir property of CQDs. Due to its up-conversion property, CQDs absorbed longer wavelength NIR light $(4700 \mathrm{~nm})$ and emitted shorter wavelength light (390 to $564 \mathrm{~nm}$ ) and successively excited $\mathrm{H}-\mathrm{TiO}_{2}$ belt to form $\mathrm{e}^{-}-\mathrm{h}^{+}$pairs (Tian 
et al., 2015). CQDs modified hydrogenated $-\gamma-\mathrm{TaON}$ heterojunction for degradation of Rhodamine B (Rh B) and Acid orange 7 (AO 7) under UV-visible-NIR light illumination (Hou et al., 2015). Under UV light irradiation, CQDs/H- $\gamma-\mathrm{TaON}$ degraded $98 \%$ of RhB after 140 min and $99 \%$ of AO 7 after 100 min which was higher than of $\mathrm{H}-\gamma-\mathrm{TaON}(80 \% \mathrm{Rh} \mathrm{B}$ and 90 $\% \mathrm{AO} 7)$ and $\gamma-\mathrm{TaON}(64 \% \mathrm{Rh} \mathrm{B}$ and $80 \% \mathrm{AO} 7)$. Under visible light irradiation, CQDs/H- $\gamma-\mathrm{TaON}$ heterojunction degraded $88 \%$ of RhB after $140 \mathrm{~min}$ and $90 \%$ of $\mathrm{AO} 7$ after 100 min which was higher than of $\mathrm{H}-\gamma-\mathrm{TaON}$ and $\gamma-\mathrm{TaON}$. Also under NIR light irradiation, CQDs/H- $\gamma-\mathrm{TaON}$ heterojunction degraded $61 \%$ of RhB after 140 min and $66 \%$ of $\mathrm{AO} 7$ after 100 min which was higher than that of $\mathrm{H}-\gamma-\mathrm{TaON}(30 \% \mathrm{Rh} \mathrm{B}$ and $50 \% \mathrm{AO} 7)$ and $\gamma-\mathrm{TaON}$ (22\% Rh B and $34 \%$ AO 7). CQDs acted as electron reservoir and trapped electrons produced from hydrogenated $-\gamma-\mathrm{TaON}$ under UV-visible light irradiation. This prevented recombination of $\mathrm{e}^{-}-\mathrm{h}^{+}$pairs, increased charge separation and enhanced photocatalytic action of heterojunction. Also, CQDs absorbed longer wavelength light, then emitted shorter wavelength light due to its up-conversion behavior. In turn, CQDs excited the hydrogenated $-\gamma-\mathrm{TaON}$ to form $\mathrm{e}^{-}-\mathrm{h}^{+}$pairs and improved NIR photocatalytic properties. The photocatalytic action of $\mathrm{CQDs} / \mathrm{H}-\gamma-\mathrm{TaON}$ heterojunction under UV-visible-NIR light illumination is shown in Fig. 11d (Hou et al., 2015).

\section{$<$ Please insert Fig. 11 here $>$}

N-CQDs modified $\mathrm{Ag}_{3} \mathrm{PO}_{4} / \mathrm{BiVO}_{4}$ heterojunction was synthesised by Zhang and coworkers for the degradation of Tetracycline (TC) under visible light irradiation (Zhang et al., 2018). After 90 min visible light irradiation, $59.8 \%$ and $24.3 \%$ of TC were removed by NCQDs $/ \mathrm{Ag}_{3} \mathrm{PO}_{4} / \mathrm{BiVO}_{4}-10$ heterojunction and $\mathrm{BiVO}_{4}$, respectively. The value of $\mathrm{k}$ for $\mathrm{TC}$ removal by $\mathrm{N}-\mathrm{CQDs} / \mathrm{Ag}_{3} \mathrm{PO}_{4} / \mathrm{BiVO}_{4}-10$ heterojunction was $1.80,2.78$ and 6.0 times more than 
that of $\mathrm{Ag}_{3} \mathrm{PO}_{4} / \mathrm{BiVO}_{4}, \mathrm{~N}-\mathrm{CQDs} / \mathrm{BiVO}_{4}$ and $\mathrm{BiVO}_{4}$ respectively. The photocatalytic activity of Z-scheme $\mathrm{BiVO}_{4} / \mathrm{N}$-CQDs/ $/ \mathrm{Ag}_{3} \mathrm{PO}_{4}$ heterojunction was higher than Type-II $\mathrm{BiVO}_{4} / \mathrm{AgPO}_{4}$ heterojunction. The introduction of $\mathrm{N}-\mathrm{CQDs}$ and $\mathrm{Ag}_{3} \mathrm{PO}_{4}$ on $\mathrm{BiVO}_{4}$ surface resulted in enhanced visible light absorption capability. N-CQDs acted as a photosensitizer and their molecular oxygen activation ability contributed to increased photocatalytic degradation action. The proposed mechanism of $\mathrm{e}^{-}-\mathrm{h}^{+}$pairs separation in $\mathrm{N}$-CQDs modified $\mathrm{Ag}_{3} \mathrm{PO}_{4} / \mathrm{BiVO}_{4}$ heterojunction is explained in Fig. 12a (Zhang et al., 2018a). A Z-scheme N-CQDs modified $\mathrm{Bi}_{2} \mathrm{O}_{4}$ heterojunction was fabricated for degradation of phenol and Methyl orange (MO) under visible light irradiation (Yue et al., 2018). The results revealed that 3-N-CQDs/ $/ \mathrm{Bi}_{2} \mathrm{O}_{4}$ showed the highest photocatalytic performance for removal of $\mathrm{MO}$ and phenol, i.e. $97.4 \%$ after $30 \mathrm{~min}$ and $96.8 \%$ after 120 min respectively. The improved photocatalytic activity of $\mathrm{N}-\mathrm{CQDs} / \mathrm{Bi}_{2} \mathrm{O}_{4}$ heterojunction is ascribed to enhanced light harvesting ability and formation of Z-scheme heterojunction between CQDs and $\mathrm{Bi}_{2} \mathrm{O}_{4}$. Hence, it promoted the effective separation of generated $\mathrm{e}^{-}-\mathrm{h}^{+}$pairs and enhanced molecular oxygen activation capacity. It was also reported that for improved photocatalytic action of heterojunction, a suitable amount of N-CQDs on $\mathrm{Bi}_{2} \mathrm{O}_{4}$ was important, i.e. excess of either photo-system I (PS I) or photo-system II (PS II) component declined photocatalytic activity. The photocatalytic mechanism of Z-scheme N-CQDs/ $/ \mathrm{Bi}_{2} \mathrm{O}_{4}$ heterojunction under visible light is shown in Fig. 12b (Yue et al., 2018). CQDs modified $\mathrm{ZnIn}_{2} \mathrm{~S}_{4}$ flowerlike heterojunction was fabricated by Liu et al. via a solvothermal process for the reduction of $\mathrm{Cr}(\mathrm{VI})$, Methyl orange (MO) and rhodamine $\mathrm{B}(\mathrm{Rh} \mathrm{B})$ under visible light irradiation (Liu et al., 2018). 0.5-CQDs/ZnIn $\mathrm{S}_{4}$ showed the highest photocatalytic behavior for reduction of $\mathrm{Cr}$ (VI) and was $93 \%$ after 40 min visible light irradiation. The photocatalytic reduction of $\mathrm{MO}$ and $\mathrm{Rh} \mathrm{B}$ over $0.5-\mathrm{CQDs} / \mathrm{ZnIn}_{2} \mathrm{~S}_{4}$ was $96 \%$ and $95 \%$ respectively. The 
synergetic effect of CQDs and $\mathrm{ZnIn}_{2} \mathrm{~S}_{4}$ improved separation efficiency and prolonged lifetime of charge carriers, hence enhanced photocatalytic activity. Also due to up-conversion behavior CQDs absorbed longer wavelength light, emitted shorter wavelength light and excited $\mathrm{ZnIn}_{2} \mathrm{~S}_{4}$ for formation of $\mathrm{e}^{-}-\mathrm{h}^{+}$pairs (Liu et al., 2018). Zhang et al. fabricated CQDs/ $\mathrm{Ag}_{3} \mathrm{PO}_{4}$ and $\mathrm{CQDs} / \mathrm{Ag} / \mathrm{Ag}_{3} \mathrm{PO}_{4}$ complex photocatalysts with improved photocatalytic action for degradation of methyl orange (MO) under visible light irradiation (Zhang et al., 2012). Among both photocatalysts, $\mathrm{CQDs} / \mathrm{Ag} / \mathrm{Ag}_{3} \mathrm{PO}_{4}$ exhibited higher photocatalytic action and degraded entire MO dye in 10 min under visible light radiation. $\mathrm{CQDs} / \mathrm{Ag}_{3} \mathrm{PO}_{4}$ and bare $\mathrm{Ag}_{3} \mathrm{PO}_{4}$ photocatalyst degraded the dye in $25 \mathrm{~min}$ and $55 \mathrm{~min}$, respectively. CQDs acted as electron reservoir to trap electrons emitted from $\mathrm{Ag}_{3} \mathrm{PO}_{4}$ nanoparticles under visible light irradiation. Due to its upconversion property, CQDs absorbed visible light and emitted shorter wavelength light (300 $530 \mathrm{~nm}$ ) which further excited $\mathrm{Ag}_{3} \mathrm{PO}_{4}$ to produce $\mathrm{e}^{-}-\mathrm{h}^{+}$pairs. The insoluble CQDs layer on $\mathrm{Ag}_{3} \mathrm{PO}_{4}$ surface protected $\mathrm{Ag}_{3} \mathrm{PO}_{4}$ and $\mathrm{Ag} / \mathrm{Ag}_{3} \mathrm{PO}_{4}$ from dissolution in an aqueous medium. Also, CQDs protected $\mathrm{Ag}_{3} \mathrm{PO}_{4}$ and $\mathrm{Ag} / \mathrm{Ag}_{3} \mathrm{PO}_{4}$ from photo-corrosion through electron transfer process and enhanced stability of $\mathrm{CQDs} / \mathrm{Ag}_{3} \mathrm{PO}_{4}$ and $\mathrm{CQDs} / \mathrm{Ag} / \mathrm{Ag}_{3} \mathrm{PO}_{4}$. The diagram representation of high photocatalytic activity and stability of CQDs in CQDs/ $/ \mathrm{Ag}_{3} \mathrm{PO}_{4}$ heterojunction is explained in Fig. 12c (Zhang et al., 2012).

\section{< Please insert Fig. 12 here >}

\section{Conclusive outlook}

In the present review, we mainly focus on CQDs modified conventional semiconductor photocatalysts for water treatment. Although attempts been made to explore the mechanism of CQDs based photocatalysis, there is still demand throwing more light on the role of CQDs in photocatalytic process. The following conclusive points can be drawn from this review: 
- In the case of CQDs modified narrow band gap photocatalyst, electron mediator nature of CQDs caused effective separation of photogenerated electrons-hole pairs.

- The up-conversion photoluminescence (UCPL) properties of CQDs facilitated the higher visible -NIR light activity in wide band gap photocatalysts.

- In Z-scheme photocatalyst, CQDS act as mediator for transfer for photogenerated electrons from $\mathrm{CB}$ of oxidative photocatalyst to $\mathrm{VB}$ of reductive photocatalyst.

- The $\pi-\pi$ interaction of CQDs are mainly responsible for enhanced adsorption of organic pollutants onto CQDS modified photocatalytic system.

- In order to minimize recombination of the photogenerated electron-hole pair, Z-scheme heterostructure involving CQDs meditated electron transfer should be preferred over conventional photocatalytic systems. The enhancement mechanism is greatly influenced by light source used for activation of a photocatalyst.

- Although attempts have been made to explore the mechanism of CQDs based photocatalysis, there is still demand for throwing more light on the role of CQDs in photocatalytic process.

- CQDs modified photocatalysts should have high recyclability over repeated catalytic cycles with no significant loss in catalytic activity. For quick separation and higher recyclability, magnetic photocatalysts can be combined with CQDs for practical applications of CQDs modified photocatalysts.

- $\quad$ Some structural and chemical manipulations of CQDs, like doping and incorporation of suitable functional groups to their surface, can be exploited as a tool for tuning their properties and, therefore, preparing more suitable CQDs modified photocatalysts in the future works. 


\section{References}

Ali, M. M., Nair, J. A., Sandhya, K. Y., 2019. Role of reactive oxygen species in the visible light photocatalytic mineralization of rhodamine B dye by P25-carbon dot photocatalyst. Dyes and Pigments.163, 274-284.

Ani, I. J., Akpan, U. G., Olutoye, M. A., \& Hameed, B. H., 2018. Photocatalytic degradation of pollutants in petroleum refinery wastewater by $\mathrm{TiO}_{2}$ and $\mathrm{ZnO}$-based photocatalysts: recent development. J. Cleaner Prod. 205, 930-954.

Antoniadou, M., Daskalaki, V. M., Balis, N., Kondarides, D. I., Kordulis, C., Lianos, P., 2011. Photocatalysis and photoelectrocatalysis using $(\mathrm{CdS}-\mathrm{ZnS}) / \mathrm{TiO}_{2}$ combined photocatalysts. Appl. Catal., B. 107(1-2), 188-196.

Aryal, S., Kim, C. K, Kim, K. W., Khil, M. S., Kim, H. Y., 2008. Multi-walled carbon nanotubes $/ \mathrm{TiO}_{2}$ composite nanofiber by electrospinning. Mater. Sci. Eng. C. 28(1), 75-79. Bajorowicz, B., Kobylański, M. P., Gołąbiewska, A., Nadolna, J., Zaleska-Medynska, A., Malankowska, A., 2018. Quantum dot-decorated semiconductor micro-and nanoparticles: A review of their synthesis, characterization and application in photocatalysis. Adv. Colloid Interface sci. 256, 352-372. 
Banerjee, S., Hemraj-Benny, T., Wong, S. S., 2005. Covalent surface chemistry of single-walled carbon nanotubes. Adv. Mater. 17(1), 17-29.

Barati, A., Shamsipur, M., Arkan, E., Hosseinzadeh, L., Abdollahi, H., 2015. Synthesis of biocompatible and highly photoluminescent nitrogen doped carbon dots from lime: analytical applications and optimization using response surface methodology. Mater. Sci. Eng. C. 47, 325332.

Barman, M. K., Patra, A., 2018. Current Status and Prospects on Chemical Structure Driven Photoluminescence behaviour of Carbon Dots. J. Photochem. Photobiol. C. 37, 1-22.

Benotti, M. J., Trenholm, R. A., Vanderford, B. J., Holady, J. C., Stanford, B. D., Snyder, S. A., 2008. Pharmaceuticals and endocrine disrupting compounds in US drinking water. Environ. Sci. Technol. 43(3), 597-603.

Chai, Y. Y., Qu, D. P., Ma, D. K., Chen, W., Huang, S., 2018. Carbon quantum dots $/ \mathrm{Zn}^{2+}$ ions doped-CdS nanowires with enhanced photocatalytic activity for reduction of 4-nitroaniline to pphenylenediamine. Appl. Surf. Sci. 450, 1-8.

Chan, W. C., Maxwell, D. J., Gao, X., Bailey, R. E., Han, M., Nie, S., 2002. Luminescent quantum dots for multiplexed biological detection and imaging. Curr. Opin. Biotechnol. 13(1), $40-46$.

Chen, B., Li, F., Li, S., Weng, W., Guo, H., Guo, T., Zhang, X., Chen, Y., Huang, T., Hong, X., You, S., 2013. Large scale synthesis of photoluminescent carbon nanodots and their application for bioimaging. Nanoscale. 5(5), 1967-1971.

Chen, J., Che, H., Huang, K., Liu, C., Shi, W., 2016. Fabrication of a ternary plasmonic photocatalyst $\mathrm{CQDs} / \mathrm{Ag} / \mathrm{Ag}_{2} \mathrm{O}$ to harness charge flow for photocatalytic elimination of pollutants. Appl. Catal., B. 192, 134-144. 
Das, R., Bandyopadhyay, R., Pramanik, P., 2018. Carbon quantum dots from natural resource: A review. Mater. Today Chem. 8, 96-109.

Di, J., Xia, J., Ge, Y., Li, H., Ji, H., Xu, H., Zhang, Q., Li, H., Li, M., 2015. Novel visible-lightdriven $\mathrm{CQDs} / \mathrm{Bi}_{2} \mathrm{WO}_{6}$ hybrid materials with enhanced photocatalytic activity toward organic pollutants degradation and mechanism insight. Appl. Catal., B. 168, 51-61.

Ding, D., Lan, W., Yang, Z., Zhao, X., Chen, Y., Wang, J., Zhang, X., Zhang, Y., Su, Q., Xie, E., 2016. A simple method for preparing $\mathrm{ZnO}$ foam/carbon quantum dots nanocomposite and their photocatalytic applications. Mater. Sci. Semicond. Process. 47, 25-31.

Feng, H., Qian, Z., 2018. Functional carbon quantum dots: a versatile platform for chemosensing and biosensing. Chem. Rec. 18(5), 491-505.

Gao, X., Cui, Y., Levenson, R. M., Chung, L. W., Nie, S., 2004. In vivo cancer targeting and imaging with semiconductor quantum dots. Nat. biotechnol. 22(8), 969.

Gautam, S., Shandilya, P., Priya, B., Singh, V.P., Raizada, P., Rai, R., Valente, M.A., Singh, P., 2017. Superparamagnetic $\mathrm{MnFe}_{2} \mathrm{O}_{4}$ dispersed over graphitic carbon sand composite and bentonite as magnetically recoverable photocatalyst for antibiotic mineralization. Sep. Purif. Technol. 172, 498-511.

Gupta, V. K., Pathania, D., Singh, P., 2014. Pectin-cerium (IV) tungstate nanocomposite and its adsorptional activity for removal of methylene blue dye. Int. J. Environ. Sci. Technol. 11(7), 2015-2024.

Hasija, V., Raizada, P., Sudhaik, A., Sharma, K., Kumar, A., Singh, P., Thakur, V. K. 2019. Recent advances in noble metal free doped graphitic carbon nitride based nanohybrids for photocatalysis of organic contaminants in water: A review. Appl. Mater. Today. 15, 494-524. 
Hou, J., Cheng, H., Yang, C., Takeda, O., Zhu, H., 2015. Hierarchical carbon quantum dots/hydrogenated- $\gamma$-TaON heterojunctions for broad spectrum photocatalytic performance. Nano Energy. 18, 143-153.

Hu, Q., Ji, M., Di, J., Wang, B., Xia, J., Zhao, Y., Li, H., 2018. Ionic liquid-induced double regulation of carbon quantum dots modified bismuth oxychloride/bismuth oxybromide nanosheets with enhanced visible-light photocatalytic activity. J. Colloid Interface Sci. 519, 263272.

Jamwal, D., Kaur, G., Raizada, P., Singh, P., Pathak, D., Thakur, P., 2015. Twin-tail surfactant peculiarity in superficial fabrication of semiconductor quantum dots: toward structural, optical, and electrical features. J. Phys. Chem. C. 119(9), 5062-5073.

Ji, M., Zhang, Z., Xia, J., Di, J., Liu, Y., Chen, R., Yin, S., Zhang, S., Li, H., 2018. Enhanced photocatalytic performance of carbon quantum dots/BiOBr composite and mechanism investigation. Chin. Chem. Lett. 29(6), 805-810.

Kaur, S., Sharma, S., Kansal, S. K., 2016. Synthesis of ZnS/CQDs nanocomposite and its application as a photocatalyst for the degradation of an anionic dye, ARS. Superlattices Microstruct. 98, 86-95.

Li, H., He, X., Kang, Z., Huang, H., Liu, Y., Liu, J., Lian, S., Tsang, C.H.A., Yang, X. Lee, S.T., 2010. Water-soluble fluorescent carbon quantum dots and photocatalyst design. Angew. Chem. Int. Ed. 49(26), 4430-4434.

Li, H., Liu, R., Kong, W., Liu, J., Liu, Y., Zhou, L., Zhang, X., Lee, S.T., Kang, Z., 2014. Carbon quantum dots with photo-generated proton property as efficient visible light controlled acid catalyst. Nanoscale. 6(2), 867-873. 
Li, H., Liu, R., Liu, Y., Huang, H., Yu, H., Ming, H., Lian, S., Lee, S.T., Kang, Z., 2012. Carbon quantum dots $/ \mathrm{Cu}_{2} \mathrm{O}$ composites with protruding nanostructures and their highly efficient (near) infrared photocatalytic behavior. J. Mater. Chem. 22(34), 17470-17475.

Li, H., Tu, W., Zhou, Y., Zou, Z., 2016. Z-Scheme Photocatalytic Systems for Promoting Photocatalytic Performance: Recent Progress and Future Challenges. Adv. Sci. 3(11), 1500389. Li, W., Zhao, C., \& Zhang, Q., 2018. Synthesis of $\mathrm{Bi} / \mathrm{BiOCl}_{-} \mathrm{TiO}_{2}-\mathrm{CQDs}$ quaternary photocatalyst with enhanced visible-light photoactivity and fast charge migration. Catal. Commun. 107, 74-77.

Li, Y., Zhang, B. P., Zhao, J. X., Ge, Z. H., Zhao, X. K., Zou, L., 2013. ZnO/carbon quantum dots heterostructure with enhanced photocatalytic properties. Appl. Surf. Sci. 279, 367-373.

Liu, B., Liu, X., Li, L., Li, J., Li, C., Gong, Y., Niu, L., Zhao, X., Sun, C.Q., 2018. ZnIn ${ }_{2} \mathrm{~S}_{4}$ flowerlike microspheres embedded with carbon quantum dots for efficient photocatalytic reduction of Cr (VI). Chin. J. Catal. 39(12), 1901-1909.

Liu, R., Huang, H., Li, H., Liu, Y., Zhong, J., Li, Y., Zhang, S., Kang, Z., 2013a. Metal nanoparticle/carbon quantum dot composite as a photocatalyst for high-efficiency cyclohexane oxidation. ACS Catal. 4(1), 328-336.

Liu, Y., Yu, Y. X., Zhang, W. D., 2013b. Carbon quantum dots-doped CdS microspheres with enhanced photocatalytic performance. J. Alloys Compd. 569, 102-110.

Low, J., Jiang, C., Cheng, B., Wageh, S., Al-Ghamdi, A. A., Yu, J., 2017. A Review of Direct Z-Scheme Photocatalysts. Small Methods. 1(5), 1700080.

Ma, Z., Ming, H., Huang, H., Liu, Y., Kang, Z., 2012. One-step ultrasonic synthesis of fluorescent $\mathrm{N}$-doped carbon dots from glucose and their visible-light sensitive photocatalytic ability. New J. Chem. 36(4), 861-864. 
Maeda, K., 2013. Z-scheme water splitting using two different semiconductor photocatalysts. ACS Catal. 3(7), 1486-1503.

Mallakpour, S., Behranvand, V., 2018. Synthesis of mesoporous recycled poly (ethylene terephthalate)/MWNT/carbon quantum dot nanocomposite from sustainable materials using ultrasonic waves: Application for methylene blue removal. J. Cleaner Prod. 190, 525-537.

Miao, R., Luo, Z., Zhong, W., Chen, S.Y., Jiang, T., Dutta, B., Nasr, Y., Zhang, Y., Suib, S.L., 2016. Mesoporous $\mathrm{TiO}_{2}$ modified with carbon quantum dots as a high-performance visible light photocatalyst. Appl. Catal., B. 189, 26-38.

Muthulingam, S., Lee, I. H., Uthirakumar, P., 2015. Highly efficient degradation of dyes by carbon quantum dots/N-doped zinc oxide (CQD/N-ZnO) photocatalyst and its compatibility on three different commercial dyes under daylight. J. Colloid Interface Sci. 455, 101-109.

Namdari, P., Negahdari, B., Eatemadi, A., 2017. Synthesis, properties and biomedical applications of carbon-based quantum dots: an updated review. Biomed. Pharmacother. 87, 209222.

Oliveira, H. G., Nery, D. C., Longo, C., 2010. Effect of applied potential on photocatalytic phenol degradation using nanocrystalline $\mathrm{TiO}_{2}$ electrodes. Appl. Catal., B: Environ. 93(3-4), 205-211.

Pan, J., Liu, J., Zuo, S., Khan, U. A., Yu, Y., Li, B., 2018. Structure of Z-scheme $\mathrm{CdS} / \mathrm{CQDs} / \mathrm{BiOCl}$ heterojunction with enhanced photocatalytic activity for environmental pollutant elimination. Appl. Surf. Sci. 444, 177-186.

Pare, B., Jonnalagadda, S. B., Tomar, H., Singh, P., Bhagwat, V. W., 2008a. ZnO assisted photocatalytic degradation of acridine orange in aqueous solution using visible irradiation. Desalin. 232(1-3), 80-90. 
Pare, B., Singh, P., Jonnalagadda, S. B., 2008b. Visible light induced heterogeneous advanced oxidation process to degrade pararosanilin dye in aqueous suspension of $\mathrm{ZnO}$. Indian J. Chem., Sect A. 47A (06), 830-835. http://nopr.niscair.res.in/handle/123456789/2017.

Priya, B., Shandilya, P., Raizada, P., Thakur, P., Singh, N., Singh, P., 2016. Photocatalytic mineralization and degradation kinetics of ampicillin and oxytetracycline antibiotics using graphene sand composite and chitosan supported BiOCl. J. Mol. Catal. A: Chem. 423, 400-413.

Qu, K., Wang, J., Ren, J., Qu, X., 2013. Carbon dots prepared by hydrothermal treatment of dopamine as an effective fluorescent sensing platform for the label-free detection of iron (III) ions and dopamine. Chem. Eur. J. 19(22), 7243-7249.

Qu, X., Yi, Y., Qiao, F., Liu, M., Wang, X., Yang, R., Meng, H., Shi, L., Du, F., 2018a. TiO2/BiOI/CQDs: Enhanced photocatalytic properties under visible-light irradiation. Ceram. Int. 44(2), 1348-1355.

Qu, Z., Wang, J., Tang, J., Shu, X., Liu, X., Zhang, Z., Wang, J., 2018b. Carbon quantum dots/ $\mathrm{KNbO}_{3}$ hybrid composites with enhanced visible-light driven photocatalytic activity toward dye waste-water degradation and hydrogen production. Mol. Catal. 445, 1-11.

Raizada, P., Gautam, S., Priya, B., Singh, P., 2016a. Preparation and photocatalytic activity of hydroxyapatite supported $\mathrm{BiOCl}$ nanocomposite for oxytetracyline removal. Adv. Mater. Lett. 7(4), 312-318.

Raizada, P., Priya, B., Thakur, P., Singh, P., 2016b. Solar light induced photodegradation of oxytetracyline using $\mathrm{Zr}$ doped $\mathrm{TiO}_{2} / \mathrm{CaO}$ based nanocomposite. Indian J. Chem., Sect A. 55A (07), 803-809. http://nopr.niscair.res.in/handle/123456789/35068.

Raizada, P., Kumari, J., Shandilya, P., Dhiman, R., Singh, V. P., Singh, P., 2017a. Magnetically retrievable $\mathrm{Bi} 2 \mathrm{WO}_{6} / \mathrm{Fe}_{3} \mathrm{O}_{4}$ immobilized on graphene sand composite for investigation of 
photocatalytic mineralization of oxytetracycline and ampicillin. Process Saf. Environ. Prot. 106, 104-116.

Raizada, P., Shandilya, P., Singh, P., Thakur, P., 2017b. Solar light-facilitated oxytetracycline removal from the aqueous phase utilizing a $\mathrm{H}_{2} \mathrm{O}_{2} / \mathrm{ZnWO}_{4} / \mathrm{CaO}$ catalytic system. J. Taibah Univ. Sci. 11(5), 689-699. https://doi.org/10.1016/j.jtusci.2016.06.004.

Raizada, P., Kumari, J., Shandilya, P., Singh, P., 2017c. Kinetics of photocatalytic mineralization of oxytetracycline and ampicillin using activated carbon supported $\mathrm{ZnO} / \mathrm{ZnWO}_{4}$. Desalin. 79, 204-213.

Raizada, P., Singh, P., Kumar, A., Sharma, G., Pare, B., Jonnalagadda, S. B., Thakur, P., 2014a. Solar photocatalytic activity of nano- $\mathrm{ZnO}$ supported on activated carbon or brick grain particles: role of adsorption in dye degradation. Appl. Catal., A. 486, 159-169.

Raizada, P., Singh, P., Kumar, A., Pare, B., Sreekantha, B., Jonnalagadda., 2014b. Zero valent iron-brick grain nanocomposite for enhanced solar-Fenton removal of malachite green. Sep. Purif. Technol. 133, 429-437.

Raizada, P., Sudhaik, A., Shandilya, P., Saini, A., Gupta, V., Singh, P., 2019a. Fabrication of $\mathrm{Ag}_{3} \mathrm{VO}_{4}$ decorated phosphorus and sulphur co-doped graphitic carbon nitride as high-dispersed photocatalyst for phenol mineralization and E.Coli disinfection, Sep. Purif. Technol. 212, 887900.

Raizada, P., Sudhaik, A., Singh, P., Shandilya, P., Gupta, V. K., Hosseini-Bandegharaei, A., Agrawal, S. 2019b. $\mathrm{Ag}_{3} \mathrm{PO}_{4}$ modified phosphorus and sulphur co-doped graphitic carbon nitride as a direct Z-scheme photocatalyst for 2, 4-dimethyl phenol degradation. J. Photochem. Photobiol. A. 374, 22-35. 
Raizada, P., Sudhaik, A., Singh, V. P., Gupta, V. K., Hosseini-Bandegharaei, A., Kumar, R., \& Singh, P. 2019c. Solar light assisted degradation of oxytetracycline from water using $\mathrm{Bi}_{2} \mathrm{O}_{3} / \mathrm{Fe}_{3} \mathrm{O}_{4}$ supported graphitic carbon nitride photocatalyst. Desalin. Water. Treat. 148, 338350.

Raizada, P., Sudhaik, A., Singh, P., Shandilya, P., Thakur, P., Jung, H., 2018. Visible light assisted photodegradation of 2, 4-dinitrophenol using $\mathrm{Ag}_{2} \mathrm{CO}_{3}$ loaded phosphorus and sulphur co-doped graphitic carbon nitride nanosheets in simulated wastewater, Arab. J. Chem. https://doi.org/10.1016/j.arabjc.2018.10.004.

Rakshit, T., Mondal, S. P., Manna, I., Ray, S. K., 2012. CdS-decorated ZnO nanorod heterostructures for improved hybrid photovoltaic devices. ACS Appl. Mater. Interface. 4(11), 6085-6095.

Reshma, V. G., Mohanan, P.V., 2018. Quantum dots: Applications and safety consequences. J. Lumin. 205, 287-298.

Shandilya, P., Mittal, D., Soni, M., Raizada, P., Hosseini-Bandegharaei, A., Saini, A. K., Singh, P., 2018. Fabrication of fluorine doped graphene and $\mathrm{SmVO}_{4}$ based dispersed and adsorptive photocatalyst for abatement of phenolic compounds from water and bacterial disinfection. J. Clean. Prod. 203, 386-399.

Shandilya, P., Mittal, D., Sudhaik, A., Soni, M., Raizada, P., Saini, A. K., Singh, P., 2019. $\mathrm{GdVO}_{4}$ modified fluorine doped graphene nanosheets as dispersed photocatalyst for mitigation of phenolic compounds in aqueous environment and bacterial disinfection. Sep. Purif. Technol. 210, 804-816. 
Sharma, G., Kumar, A., Naushad, M., Kumar, A., Ala'a, H., Dhiman, P., Ghfar, A.A., Stadler, F.J., Khan, M.R., 2018. Photoremediation of toxic dye from aqueous environment using monometallic and bimetallic quantum dots based nanocomposites. J. Cleaner Prod. 172, 29192930.

Shen, T., Wang, Q., Guo, Z., Kuang, J., Cao, W., 2018. Hydrothermal synthesis of carbon quantum dots using different precursors and their combination with $\mathrm{TiO}_{2}$ for enhanced photocatalytic activity. Ceram. Int. 44(10), 11828-11834.

Shi, W., Guo, F., Yuan, S., 2017. In situ synthesis of Z-scheme $\mathrm{Ag}_{3} \mathrm{PO}_{4} / \mathrm{CuBi}_{2} \mathrm{O}_{4}$ photocatalysts and enhanced photocatalytic performance for the degradation of tetracycline under visible light irradiation. Appl. Catal., B. 209, 720-728.

Singh, P. Borthakur, A., 2018. A review on biodegradation and photocatalytic degradation of organic pollutants: A bibliometric and comparative analysis. J. Cleaner Prod. 196, 1669-1680. Singh, P., Gautam, S., Shandilya, P., Priya, B., Singh, V. P., Raizada, P., 2017. Graphene bentonite supported $\mathrm{ZnFe}_{2} \mathrm{O}_{4}$ as superparamagnetic photocatalyst for antibiotic degradation. Adv. Mater. Lett. 8(3), 229-238.

Singh, P., Priya, B., Shandilya, P., Raizada, P., Singh, N., Pare, B., \& Jonnalagadda, S. B. 2016. Photocatalytic mineralization of antibiotics using $60 \% \mathrm{WO} / \mathrm{BiOCl}$ stacked to graphene sand composite and chitosan. Arab. J. Chem. https://doi.org/10.1016/j.arabjc.2016.08.005.

Singh, P., Raizada, P., Pathania, D., Kumar, A., Thakur, P., 2013a. Preparation of BSA-ZnWO 4 nanocomposites with enhanced adsorptional photocatalytic activity for methylene blue degradation. Int. J. Photoenergy. http://dx.doi.org/10.1155/2013/726250. 
Singh, P., Raizada, P., Pathania, D., Sharma, G., Sharma, P., 2013b. Microwave induced KOH activation of guava peel carbon as an adsorbent for congo red dye removal from aqueous phase. Indian J. Chem. Technol. 20(5), 305-311. http://nopr.niscair.res.in/handle/123456789/21463.

Singh, P., Raizada, P., Suadhik, A., Shandilya, P., Thakur, P., Agarwal, S., Gupta, V. K., 2018a. Enhanced photocatalytic activity and stability of $\mathrm{AgBr} / \mathrm{BiOBr} /$ graphene heterojunction for phenol degradation under visible light. J. Saudi Chem. Soc. https://doi.org/10.1016/j.jscs.2018.10.005.

Singh, P., Shandilya, P., Raizada, P., Sudhaik, A., Rahmani-Sani, A., Hosseini-Bandegharaei, A., 2018b. Review on various strategies for enhancing photocatalytic activity of graphene based $\begin{array}{lllll}\text { nanocomposites for } & \text { water }\end{array}$ https://doi.org/10.1016/j.arabjc.2018.12.001.

Smith, Y. R., Kar, A., Subramanian, V., 2009. Investigation of physicochemical parameters that influence photocatalytic degradation of methyl orange over $\mathrm{TiO}_{2}$ nanotubes. Ind. Eng. Chem. Res. 48(23), 10268-10276.

Sudhaik, A., Raizada, P., Shandilya, P., Jeong, D. Y., Lim, J. H., Singh, P., 2018a. Review on fabrication of graphitic carbon nitride based efficient nanocomposites photodegradation of aqueous phase organic pollutants. J. Ind. Eng. Chem. 67, 28-51.

Sudhaik, A., Raizada, P., Shandilya, P., Singh, P., 2018b. Magnetically recoverable graphitic carbon nitride and $\mathrm{NiFe}_{2} \mathrm{O}_{4}$ based magnetic photocatalyst for degradation of oxytetracycline antibiotic in simulated wastewater under solar light. J. Environ. Chem. Eng. 6(4), 3874-3883.

Sun, C., Xu, Q., Xie, Y., Ling, Y., Jiao, J., Zhu, H., Zhao, J., Liu, X., Hu, B., Zhou, D., 2017. High-efficient one-pot synthesis of carbon quantum dots decorating $\mathrm{Bi}_{2} \mathrm{MoO}_{6}$ nanosheets 
heterostructure with enhanced visible-light photocatalytic properties. J. Alloys Compd. 723, 333344.

Tian, J., Leng, Y., Zhao, Z., Xia, Y., Sang, Y., Hao, P., Liu, H., 2015. Carbon quantum dots/hydrogenated $\mathrm{TiO}_{2}$ nanobelt heterostructures and their broad spectrum photocatalytic properties under UV, visible, and near-infrared irradiation. Nano Energy. 11, 419-427.

Wang, H., Liu, S., Wang, H., Jiang, W., 2010. Solar photocatalytic decomposition of two azo dyes on multi-walled carbon nanotubes (MWCNTs)/ $/ \mathrm{TiO}_{2}$ composites. Front. Environ. Sci. Eng. Chin. 4(3), 311-320.

Wang, H., Wei, Z., Matsui, H., Zhou, S., 2014. $\mathrm{Fe}_{3} \mathrm{O}_{4} /$ carbon quantum dots hybrid nanoflowers for highly active and recyclable visible-light driven photocatalyst. J. Mater. Chem. A. 2(38), $15740-15745$.

Wang, K., Gao, Z., Gao, G., Wo, Y., Wang, Y., Shen, G., Cui, D., 2013. Systematic safety evaluation on photoluminescent carbon dots. Nanoscale Res. Lett. 8(1), 122.

Wang, P., Li, X., Fang, J., Li, D., Chen, J., Zhang, X., Shao, Y. He, Y., 2016. A facile synthesis of $\mathrm{CdSe}$ quantum dots-decorated anatase $\mathrm{TiO}_{2}$ with exposed $\left\{\begin{array}{lll}0 & 0 & 1\end{array}\right\}$ facets and its superior photocatalytic activity. Appl. Catal., B. 181, 838-847.

Wu, W., Zhan, L., Fan, W., Song, J., Li, X., Li, Z., Wang, R., Zhang, J., Zheng, J., Wu, M., Zeng, H., 2015. $\mathrm{Cu}-\mathrm{N}$ dopants boost electron transfer and photooxidation reactions of carbon dots. Angew. Chem. Int. Ed. 54(22), 6540-6544.

Xu, X., Ray, R., Gu, Y., Ploehn, H. J., Gearheart, L., Raker, K., Scrivens, W. A., 2004. Electrophoretic analysis and purification of fluorescent single-walled carbon nanotube fragments. J. Am. Chem. Soc. 126(40), 12736-12737. 
Yang, Z.C., Wang, M., Yong, A.M., Wong, S.Y., Zhang, X.H., Tan, H., Chang, A.Y., Li, X., Wang, J., 2011. Intrinsically fluorescent carbon dots with tunable emission derived from hydrothermal treatment of glucose in the presence of monopotassium phosphate. Chem. Commun. 47(42), 11615-11617.

Yu, H., Zhang, H., Huang, H., Liu, Y., Li, H., Ming, H., Kang, Z., 2012. ZnO/carbon quantum dots nanocomposites: one-step fabrication and superior photocatalytic ability for toxic gas degradation under visible light at room temperature. New J. Chem. 36(4), 1031-1035.

Yu, X., Liu, J., Yu, Y., Zuo, S., Li, B., 2014. Preparation and visible light photocatalytic activity of carbon quantum dots/ $\mathrm{TiO}_{2}$ nanosheet composites. Carbon. 68, 718-724.

Yue, X., Miao, X., Ji, Z., Shen, X., Zhou, H., Kong, L., Zhu, G., Li, X., Shah, S.A., 2018. Nitrogen-doped carbon dots modified dibismuth tetraoxide microrods: A direct Z-scheme photocatalyst with excellent visible-light photocatalytic performance. J. Colloid Interface Sci. 531, 473-482.

Zhang, H., Huang, H., Ming, H., Li, H., Zhang, L., Liu, Y., Kang, Z., 2012. Carbon quantum dots $/ \mathrm{Ag}_{3} \mathrm{PO}_{4}$ complex photocatalysts with enhanced photocatalytic activity and stability under visible light. J. Mater. Chem. 22(21), 10501-10506.

Zhang, J., Yan, M., Yuan, X., Si, M., Jiang, L., Wu, Z., Wang, H., Zeng, G., 2018a. Nitrogen Doped Carbon Quantum Dots Mediated Silver Phosphate/Bismuth Vanadate Z-scheme Photocatalyst for Enhanced Antibiotic Degradation. J. Colloid Interface Sci. 529, 11-22.

Zhang, P., Hou, D., O’Connor, D., Li, X., Pehkonen, S., Varma, R. S., Wang, X., 2018b. Green and Size-Specific Synthesis of Stable $\mathrm{Fe}-\mathrm{Cu}$ Oxides as Earth-Abundant Adsorbents for Malachite Green Removal. ACS Sustainable Chem. Eng. 6(7), 9229-9236. 
Zhang, X., Wang, Y., Liu, B., Sang, Y., Liu, H., 2017. Heterostructures construction on $\mathrm{TiO}_{2}$ nanobelts: A powerful tool for building high-performance photocatalysts. Appl. Catal., B. 202, 620-641.

Zhang, Y. Y., Wu, M., Wang, Y. Q., He, X. W., Li, W. Y., Feng, X. Z., 2013. A new hydrothermal refluxing route to strong fluorescent carbon dots and its application as fluorescent imaging agent. Talanta. 117, 196-202.

Zhang, Z., Lin, S., Cui, W., Li, X., Li, H., 2019. Enhanced photocatalytic activity of $\mathrm{Ag} / \mathrm{CQD} / \mathrm{Bi}_{2} \mathrm{O}_{2} \mathrm{CO}_{3}$ composite photocatalyst under full-spectrum light. Mater. Lett. 234, 264268.

Zhao, D., Yang, X., Chen, C., Wang, X., 2013. Enhanced photocatalytic degradation of methylene blue on multiwalled carbon nanotubes-TiO2. J. Colloid Interface Sci. 398, 234-239.

Zhao, F., Rong, Y., Wan, J., Hu, Z., Peng, Z., Wang, B., 2018. High photocatalytic performance of carbon quantum dots/TNTs composites for enhanced photogenerated charges separation under visible light. Catal. Today. 315, 162-170.

Zheng, L., Zheng, Y., Chen, C., Zhan, Y., Lin, X., Zheng, Q., Wei, K., Zhu, J., 2009. Network structured $\mathrm{SnO}_{2} / \mathrm{ZnO}$ heterojunction nanocatalyst with high photocatalytic activity. Inorg. Chem. 48(5), 1819-1825.

Zhou, J., Zhou, H., Tang, J., Deng, S., Yan, F., Li, W., Qu, M., 2017. Carbon dots doped with heteroatoms for fluorescent bioimaging: a review. Mikrochim. Acta. 184(2), 343-368.

Zhou, P., Yu, J., Jaroniec, M., 2014. All-solid-state Z-scheme photocatalytic systems. Adv. Mater. 26(29), 4920-4935. 
Zhu, S., Meng, Q., Wang, L., Zhang, J., Song, Y., Jin, H., Zhang, K., Sun, H., Wang, H., Yang, B., 2013. Highly photoluminescent carbon dots for multicolor patterning, sensors, and bioimaging. Angew. Chem. 125(14), 4045-4049.

Zuo, P., Lu, X., Sun, Z., Guo, Y., He, H., 2016. A review on syntheses, properties, characterization and bioanalytical applications of fluorescent carbon dots. Mikrochim. Acta. 183(2), 519-542. 


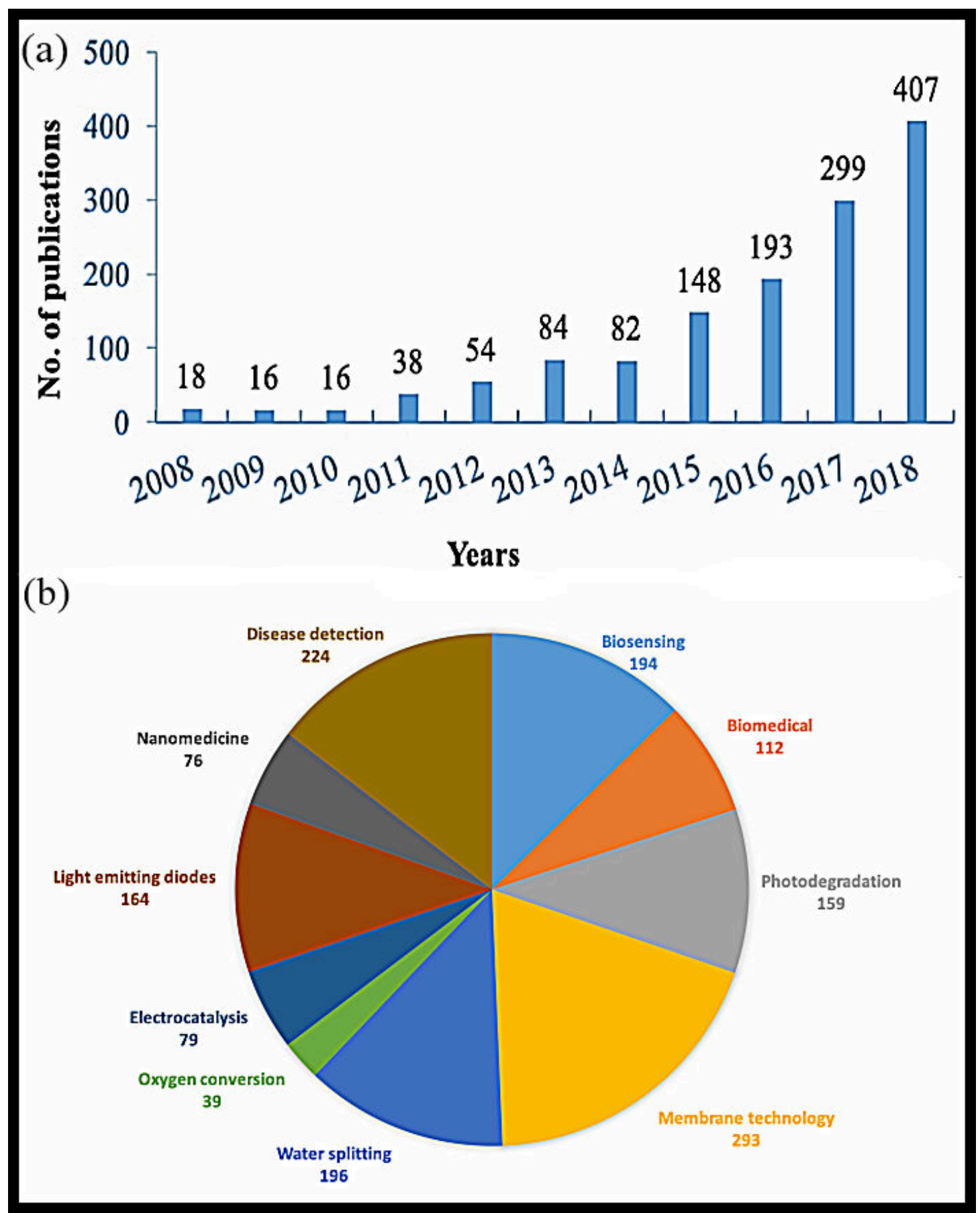

Fig. 1.

Fig 1 (a) Number of Publications per year on carbon quantum dots based photocatalyst from 2008 to 2018 on dated 25 Nov, 2018. (b) Various photo catalytic applications of carbon quantum dots ( Search engine, Scopus, key word Carbon quantum dos + photocatalyst). 


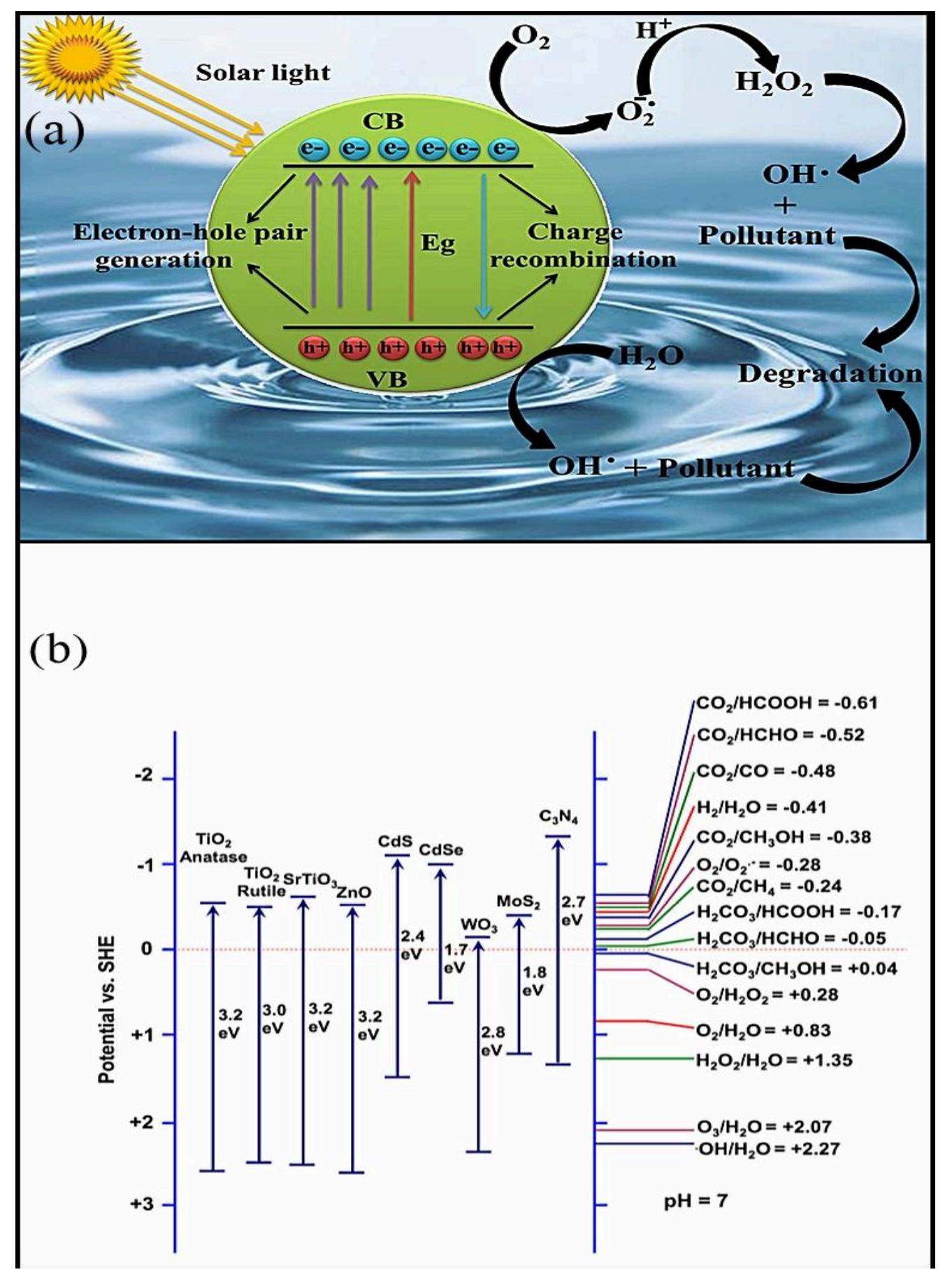

Fig. 2. (a) Basic photocatalytic mechanism of a photocatalyst depicting degradation of organic pollutants present in water (With permission from Elsevier, license number $4471830715641)$

(b) Band-edge positions and potentials for different redox couples in water of semiconductor photocatalysts (With permission from ACS publications). 


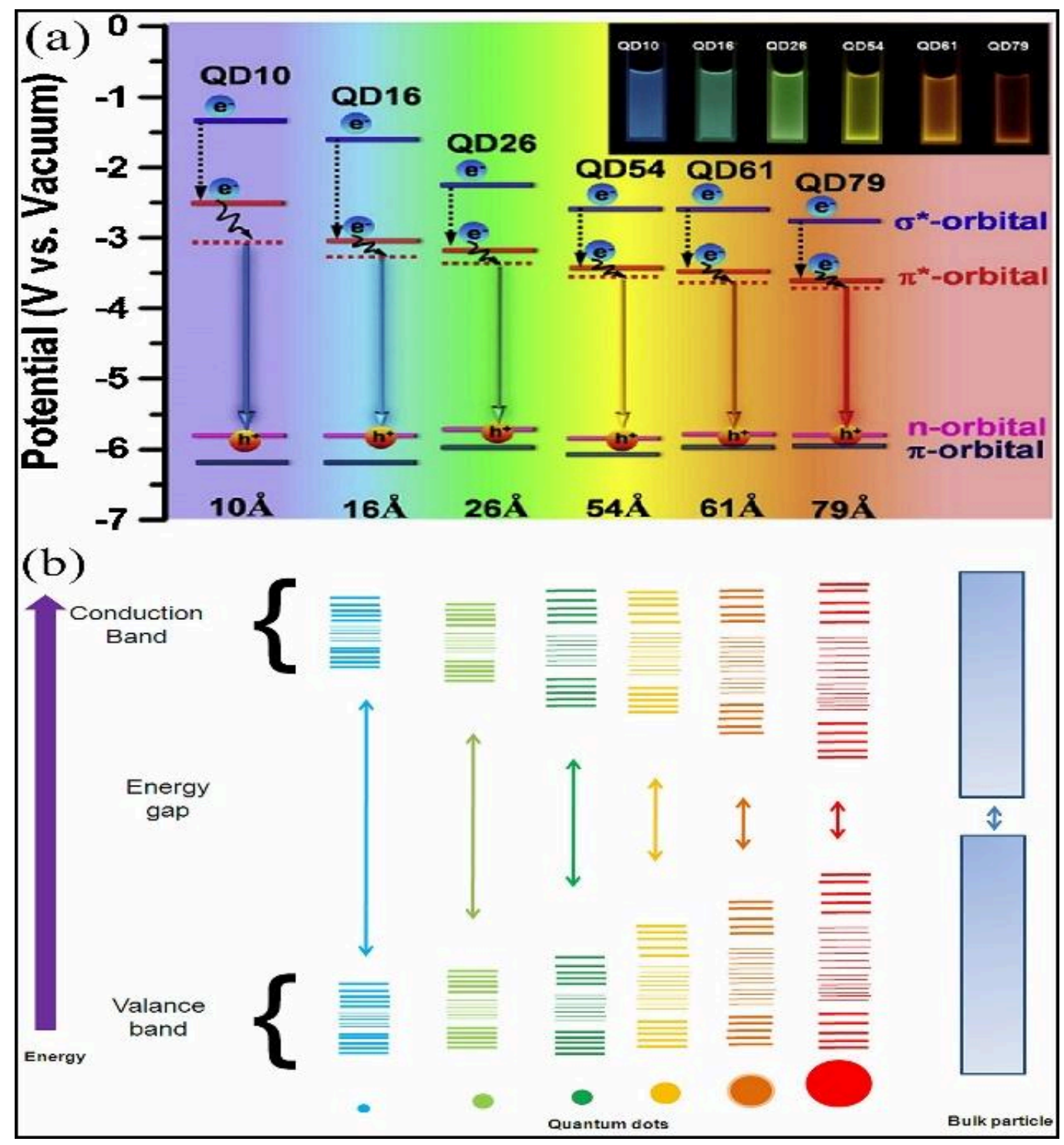

Fig. 3. (a) Quantum confinement effect of carbon quantum dots and their associated $n-\pi^{*}$ transition (b) Schematic illustration of size tunable optical properties of carbon quantum dots depicting increase in emission wavelength with increasing carbon quantum dots size (With permission from Elsevier, license number 4471831400246, 4471840225940). 


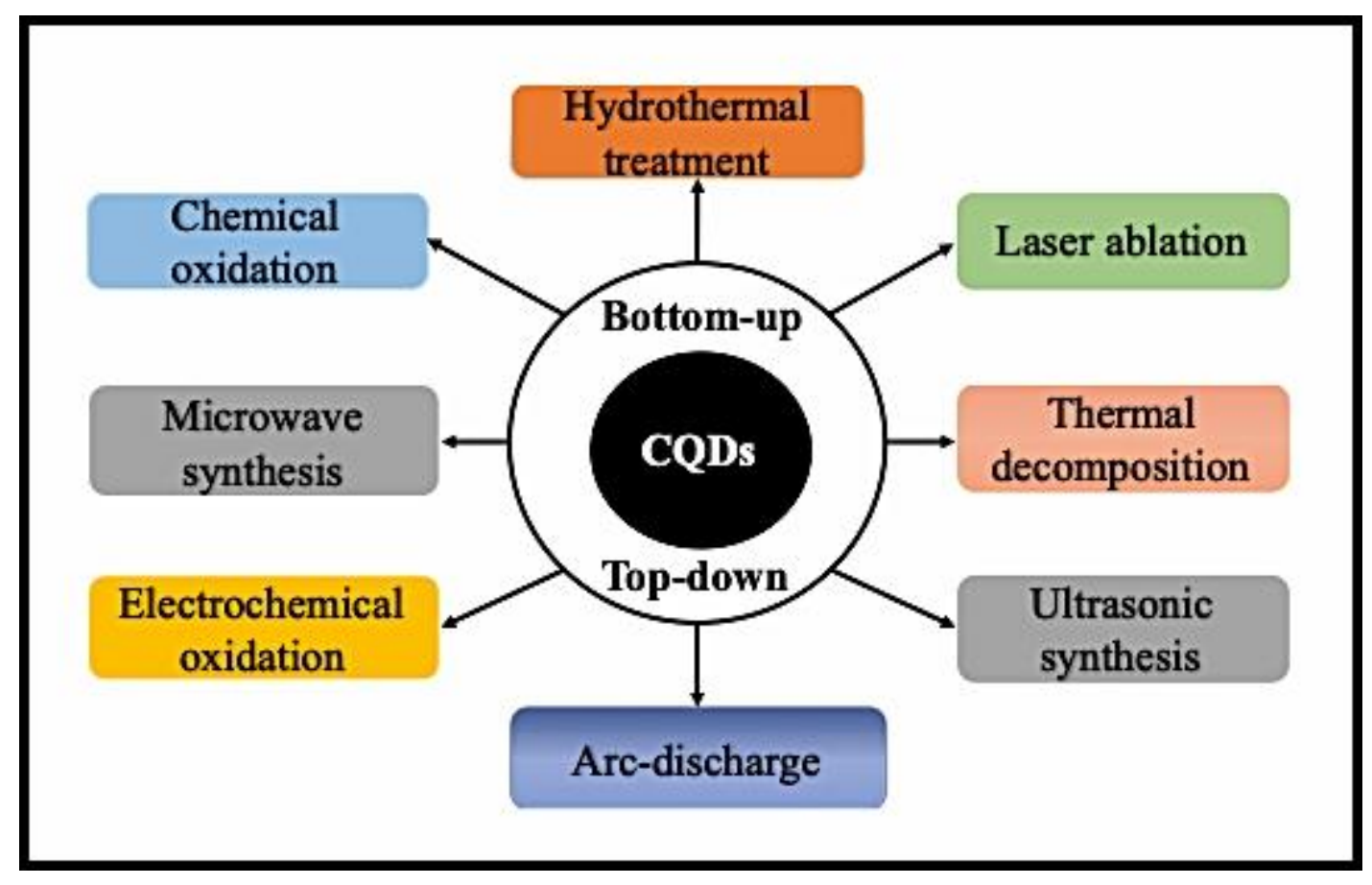

Fig. 4. Various top-down and bottom-up approaches for synthesis of carbon quantum dots. 


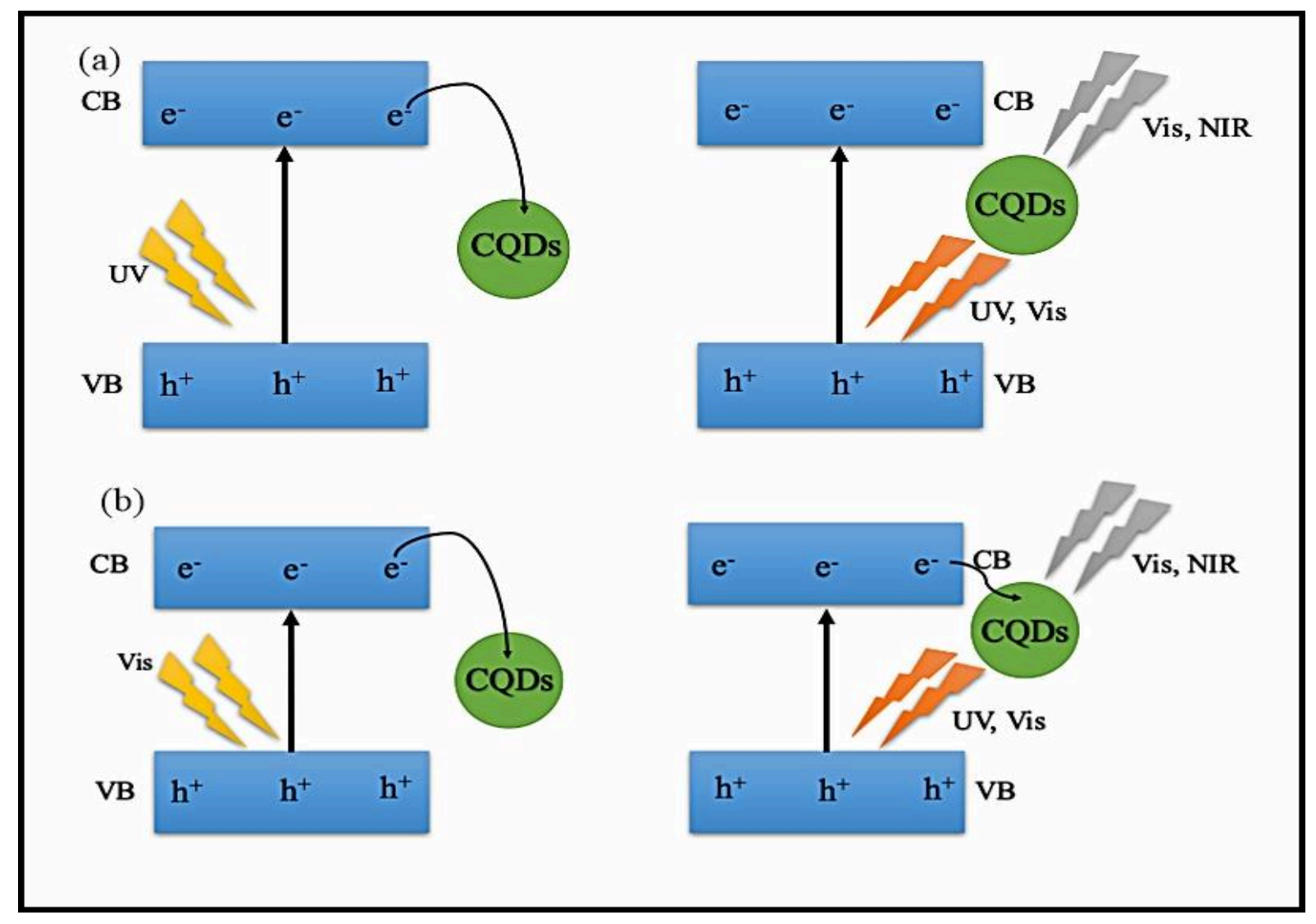

Fig. 5. Mechanism of photocatalytic excitation of CQDs for (a) wide band gap and (b) narrow band gap semiconductor photocatalysts in which CQDs act as an electron reservoir and up-conversion agent. 


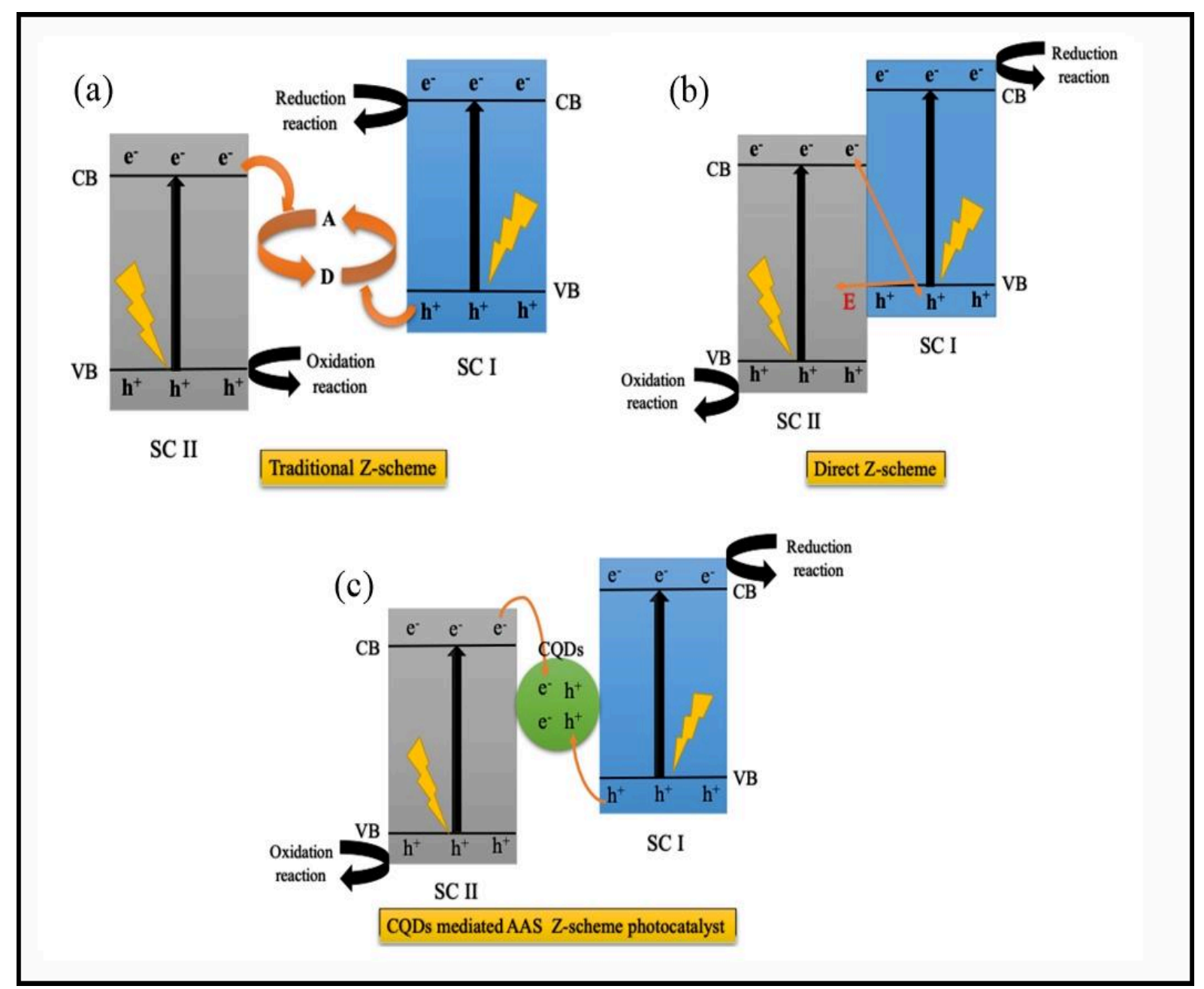

Fig. 6. Mechanism of photogenerated electron transfer in (a) Traditional Z-scheme (b) Direct Z-scheme and (c) CQDs mediated AAS Z-scheme photocatalyst. 


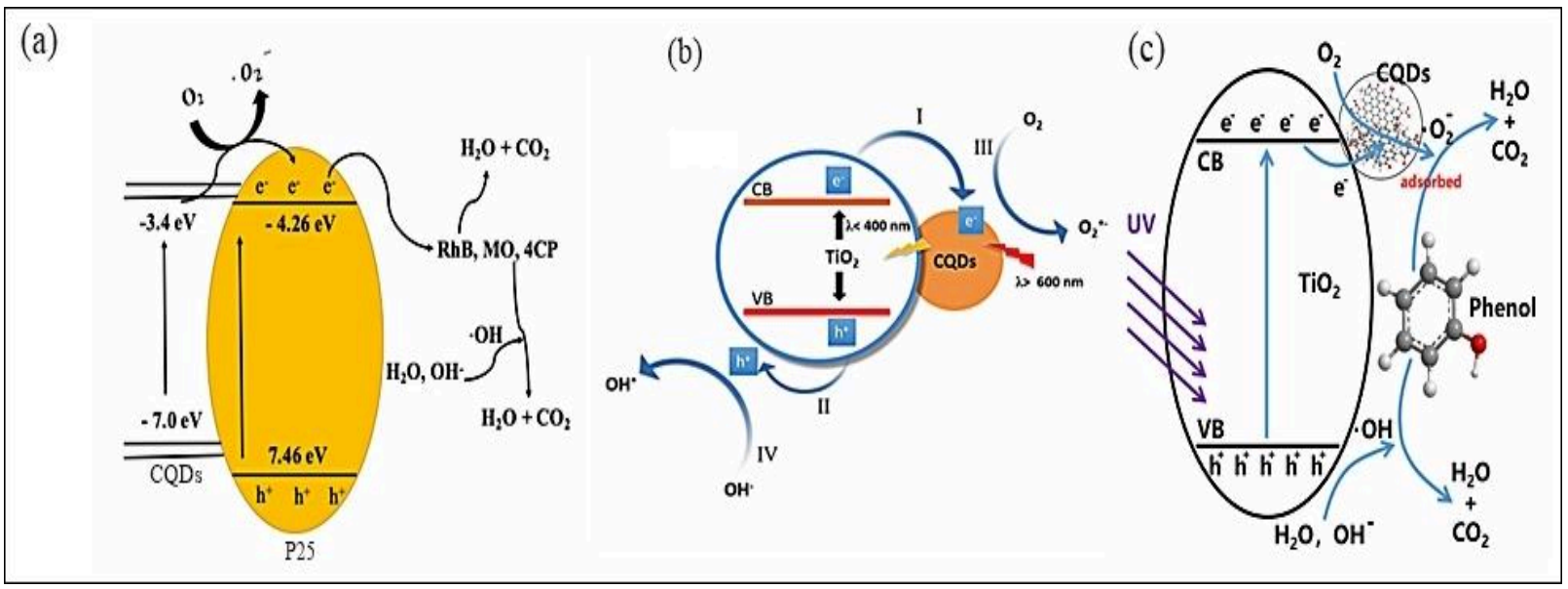

Fig.7. Proposed mechanism for photocatalytic degradation of (a) RhB, MO and 4CP over wide band gap P25/CQDs photocatalyst composite (b) methylene blue (MB) (c) phenol and over wide band gap $\mathrm{CQDs} / \mathrm{TiO}_{2}$ photocatalyst composite (With permission from Elsevier, license number 4517471378120, 4517480195774). 


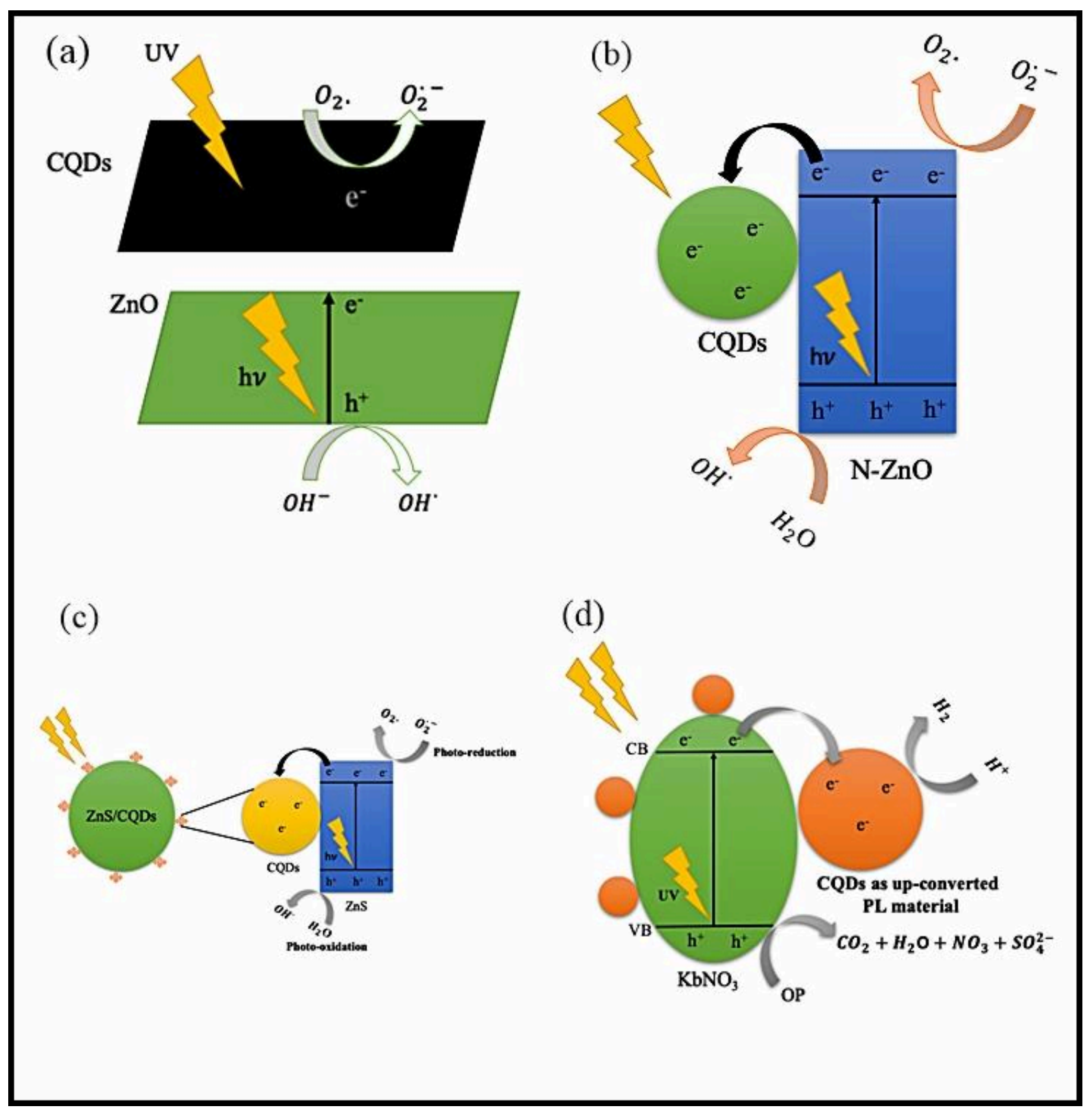

Fig. 8. Schematic representation of charge transfer mechanism of (a) CQDs/ZnO (b) CQDs/N-ZnO (c) $\mathrm{CQDs} / \mathrm{ZnS}$ (d) $\mathrm{CQDs} / \mathrm{KNBO}_{3}$ wide band gap photocatalyst composite (With permission from Elsevier, license number 4517480704264, 4517480925940, 4517500682271, 4517510137799). 


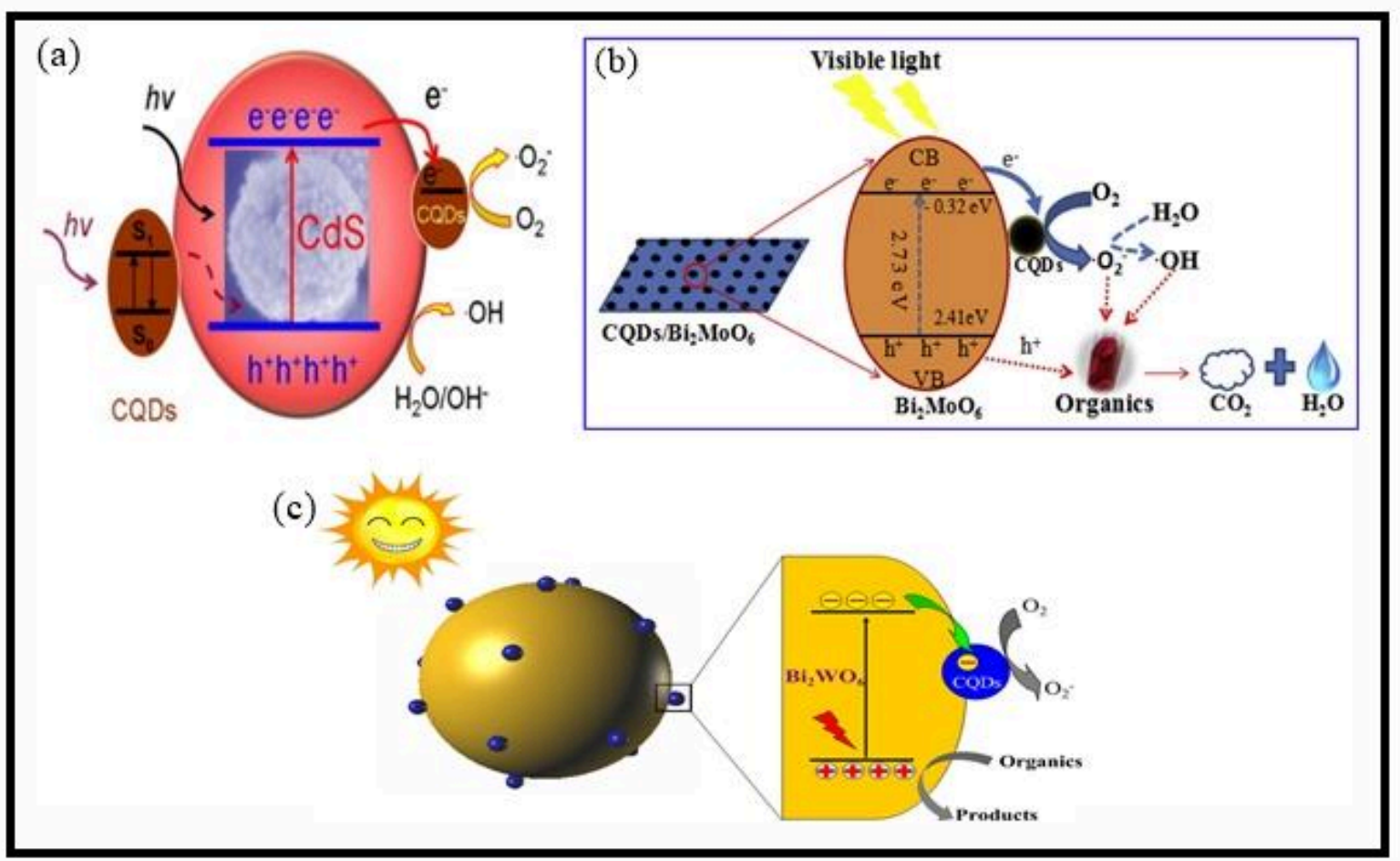

Fig.9. Schematic representation of charge transfer mechanism of (a) CQDs/CdS, (b) $\mathrm{CQDs} / \mathrm{Bi}_{2} \mathrm{MoO}_{6}$ (c) $\mathrm{CQDs} / \mathrm{Bi}_{2} \mathrm{WO}_{6}$ narrow band gap photocatalyst composite (With permission from Elsevier, license number 4517510659557, 4474120216249, 4517511222302). 
(a)

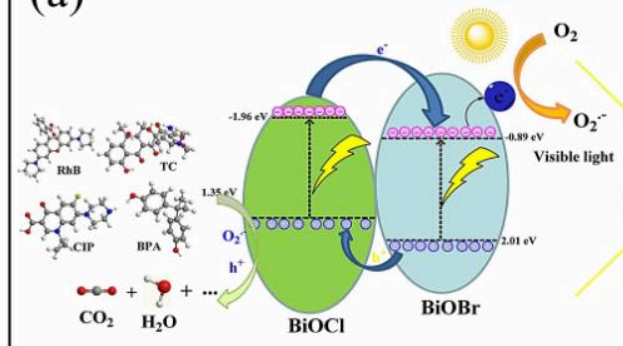

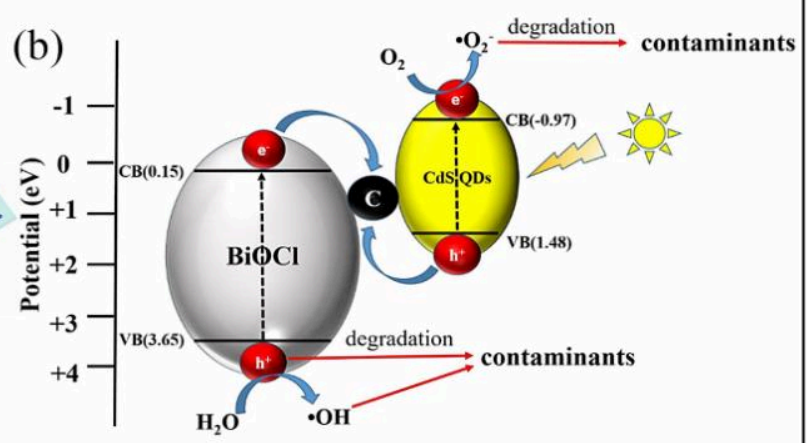

(c)

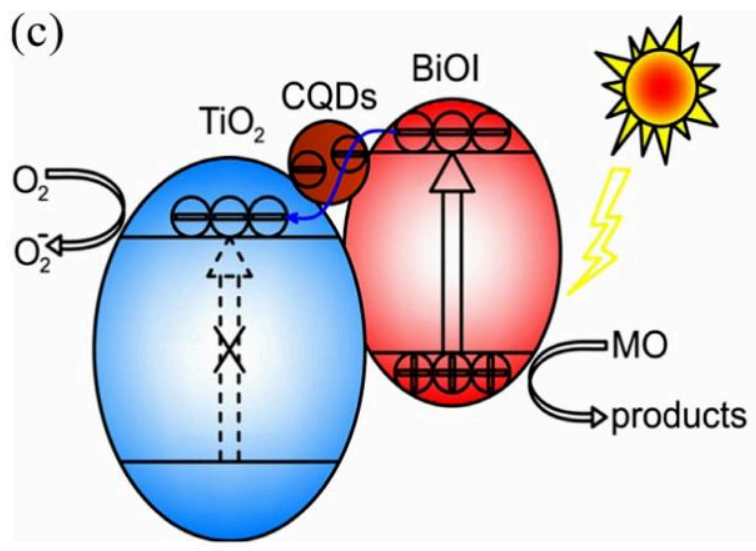

(d)

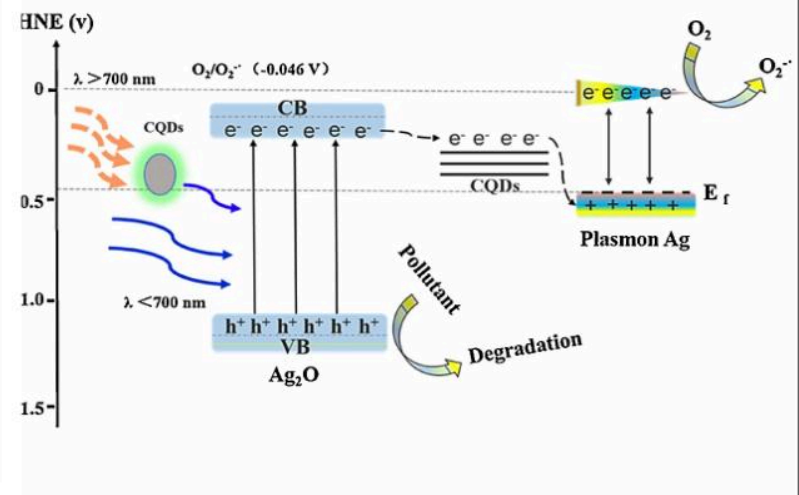

Fig.10. Schematic representation of charge transfer and photocatalytic degradation mechanism of (a) $\mathrm{CQDs} / \mathrm{BiOCl} / \mathrm{BiOBr}$ (b) $\mathrm{CQDs} / \mathrm{BiOCl} / \mathrm{CdS}$ (c) $\mathrm{CQDs} / \mathrm{TiO} \mathrm{O}_{2} / \mathrm{BiOI}$ and (d) $\mathrm{CQDs} / \mathrm{Ag} / \mathrm{Ag}_{2} \mathrm{O}$ Z- scheme heterojunctions (With permission from Elsevier, license number 4517520205318, 4471871490864, 4471880432210, 4517521384471). 

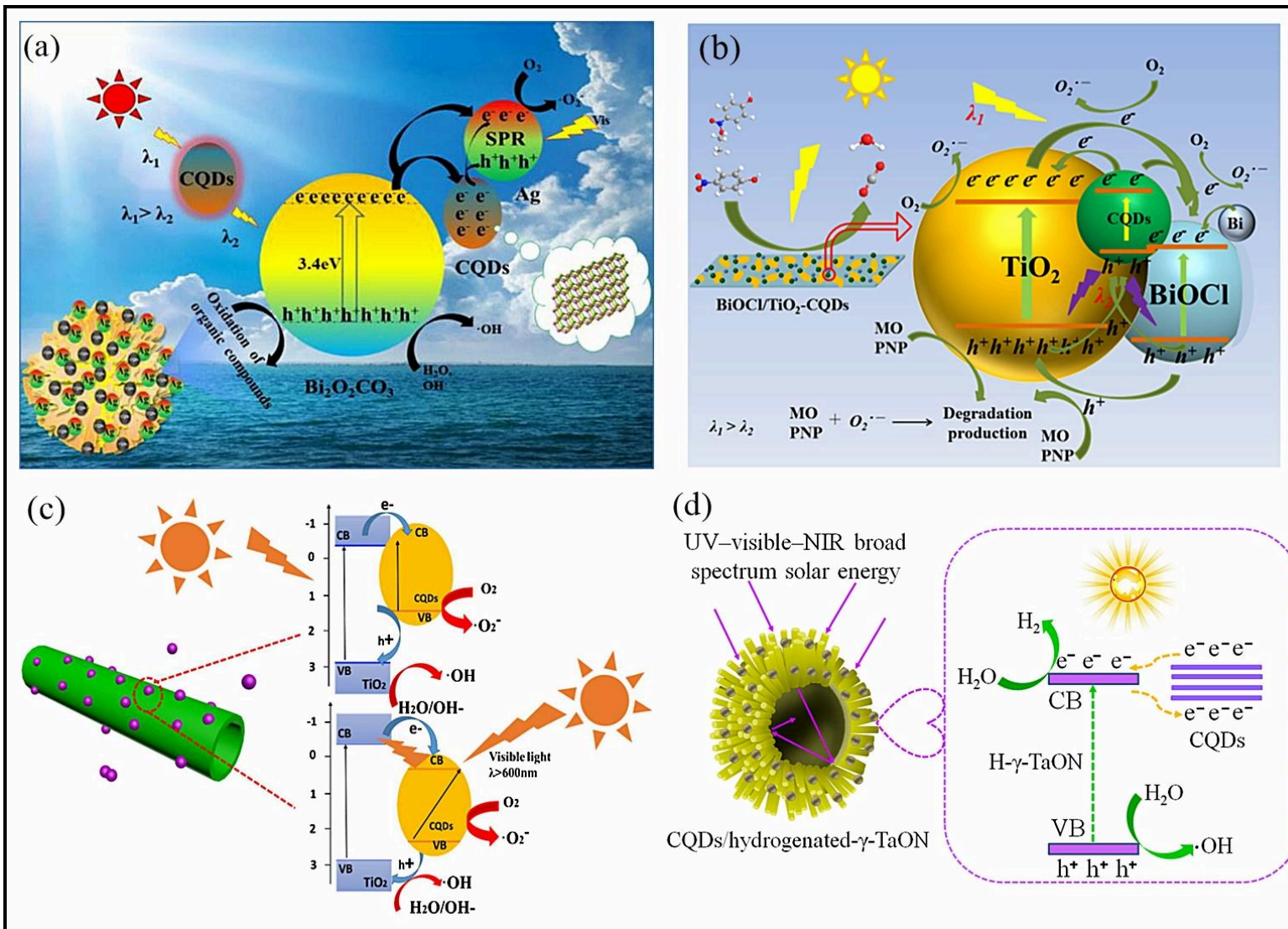

(d)

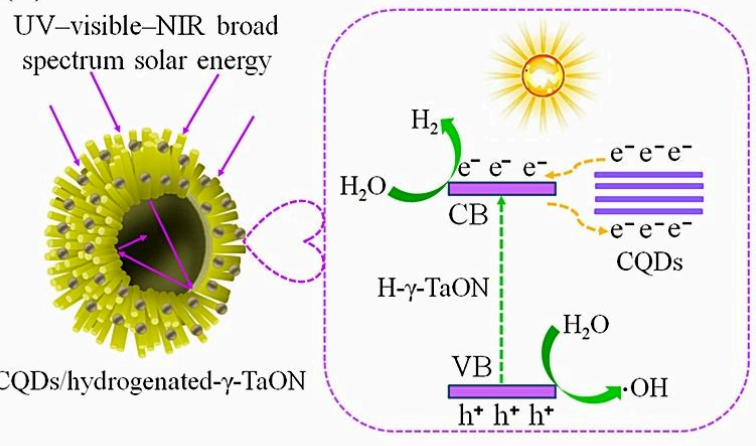

Fig.11. Various mechanistic approaches displaying organic wastewater degradation by (a) $\mathrm{Ag} / \mathrm{CQDs} / \mathrm{Bi}_{2} \mathrm{O}_{2} \mathrm{CO}_{3} \quad$ (b) $\mathrm{Bi} / \mathrm{BiOCl} / \mathrm{TiO} 2 / \mathrm{CQDs} \quad$ (c) $\mathrm{CQDs} / \mathrm{TNTs}$ and (d) CQDs/hydrogenated $-\gamma-\mathrm{TaON}$ heterojunctions (With permission from Elsevier, license number 4517560513929, 4474120337690, 4472850808917, 4517560678031). 


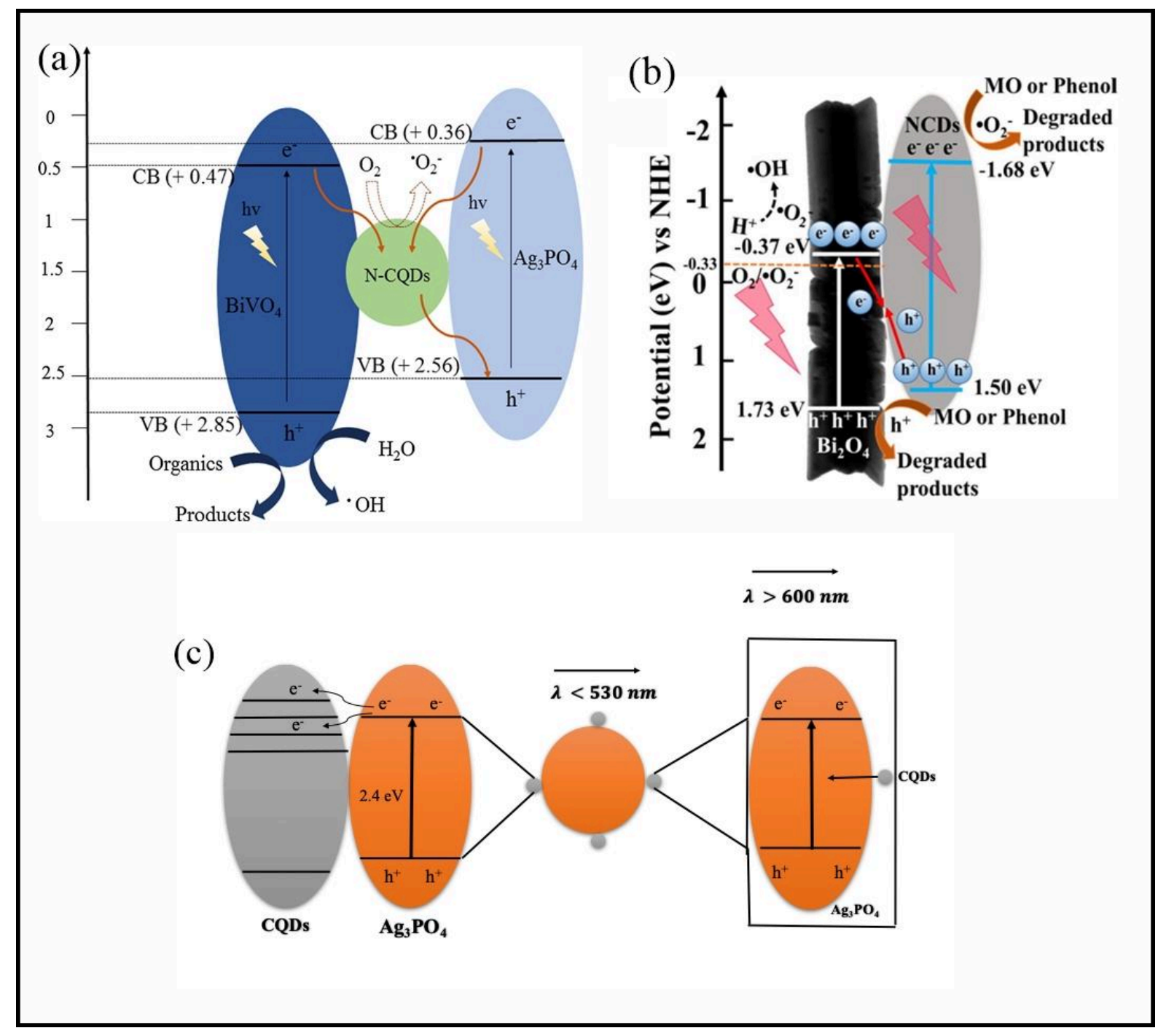

Fig.12. Schematic representation of charge transfer mechanism of (a) N$\mathrm{CQDs} / \mathrm{BiVO}_{4} / \mathrm{Ag}_{3} \mathrm{PO}_{4}$ (b) $\mathrm{N}-\mathrm{CQDs} / \mathrm{Bi}_{2} \mathrm{O}_{4}$ heterojunction (c) Diagram representation of high photocatalytic activity and stability of CQDs in $\mathrm{CQDs} / \mathrm{Ag}_{3} \mathrm{PO}_{4}$ heterojunction (With permission from Elsevier, license number 4517561187973, 4517570033645 and Royal Society of Chemistry). 

Table 1. Previous researches in the application of CQDs modified composites/ heterojunction photocatalysts for exclusion of impurities present in wastewater.

\begin{tabular}{|c|c|c|c|c|c|c|}
\hline $\begin{array}{c}\text { Composite/ } \\
\text { heterojunction }\end{array}$ & $\begin{array}{l}\text { Method of } \\
\text { synthesis }\end{array}$ & Reaction conditions & Effect of CQDs & $\begin{array}{c}\text { Pollutan } \\
\text { ts }\end{array}$ & $\begin{array}{c}\text { Degradation } \\
\text { time and light } \\
\text { source }\end{array}$ & $\begin{array}{c}\text { Referenc } \\
\text { es }\end{array}$ \\
\hline $\mathrm{CQDs} / \mathrm{TiO}_{2}$ & $\begin{array}{c}\text { hydrotherma } \\
1\end{array}$ & $\begin{array}{c}\mathrm{CQDs} / \mathrm{TiO}_{2}: \mathrm{P} 25+ \\
\text { ethanol }+\mathrm{TiO}_{2}, 140 \\
{ }^{\circ} \mathrm{C} \text { for } 4 \mathrm{~h}\end{array}$ & $\begin{array}{c}\text { Degradation rate of } \\
3 \% \mathrm{C} / \mathrm{TiO}_{2} \text { is times } \\
\text { higher than that of } \\
\text { pristine } \mathrm{TiO}_{2}\end{array}$ & $\mathrm{Cr}(\mathrm{VI})$ & $\begin{array}{c}60 \mathrm{~min}, \\
\text { visible light } \\
\text { with cut off } \\
\text { filter }(420 \mathrm{~nm})\end{array}$ & $\begin{array}{l}\text { Choi et } \\
\text { al., } 2018\end{array}$ \\
\hline $\mathrm{CQDs} / \mathrm{TiO}_{2}$ & $\begin{array}{c}\text { CQDs: } \\
\text { ultrasonic- } \\
\text { hydrotherma } \\
1 \\
\mathrm{TiO}_{2:} \text { sol-gel }\end{array}$ & $\begin{array}{c}\mathrm{TiO}_{2} \text { : L-Ascorbic } \\
\text { acid, titanium } \\
\text { isopropoxide }+1- \\
\text { butanol + P123, } 120 \\
{ }^{\circ} \mathrm{C} \text { for } 4 \mathrm{~h} \text {; CQDs: L- } \\
\text { Ascorbic + ethanol, } \\
160^{\circ} \mathrm{C} \text { for } 4 \mathrm{~h} .\end{array}$ & $\begin{array}{c}5 \% \text { CQDs/meso- } \\
\text { Ti-450 removed } 98 \\
\% \text { MB and } 10 \% \\
\text { P25 }\end{array}$ & MB & $\begin{array}{l}60 \text { min, } 1000 \\
\text { W halogen } \\
\text { lamp with } \\
\text { cutoff filter }(\lambda \\
>450 \mathrm{~nm})\end{array}$ & $\begin{array}{l}\text { Miao et } \\
\text { al., } 2016\end{array}$ \\
\hline CQDs/ZnO & Sol gel & $\begin{array}{c}\text { CQDs: Graphite } \\
\text { powder }+\mathrm{H}_{2} \mathrm{SO}_{4}+ \\
\mathrm{HNO}_{3}+\mathrm{Na}_{2} \mathrm{CO}_{3} \text { ( to } \\
\text { adjust pH), stirred at } \\
80{ }^{\circ} \mathrm{C} \text { for } 24 \mathrm{~h} \\
\\
\mathrm{CQDs} / \mathrm{ZnO}: \\
\mathrm{Zn}\left(\mathrm{NO}_{3}\right)_{2} \cdot 6 \mathrm{H}_{2} \mathrm{O}+ \\
\mathrm{CH}_{3} \mathrm{OCH}_{2} \mathrm{CH}_{2} \mathrm{OH} \\
\text { annealed at } 500{ }^{\circ} \mathrm{C} \\
\text { for } 30 \text { min }\end{array}$ & $\begin{array}{c}\text { Degradation rate of } \\
\text { (4 layers) } \\
\text { CQDs/ZnO was } 3 \\
\text { times more than } \\
\text { bare } \mathrm{ZnO}\end{array}$ & $\mathrm{Rh} B$ & $\begin{array}{c}2 \mathrm{~h}, 18 \mathrm{~W} \\
\text { ultraviolet } \\
\text { lamp cutoff } \\
\text { filter }(\lambda>365 \\
\mathrm{nm})\end{array}$ & $\begin{array}{c}\text { Li et al., } \\
2013\end{array}$ \\
\hline CQDs/ZnO & $\begin{array}{l}\text { CQDs/ZnO: } \\
\text { hydrotherma } \\
1 \text { method }\end{array}$ & $\begin{array}{l}\text { CQDs: D-fructose + } \\
\mathrm{NaOH} \text {, heated at } 50 \\
{ }^{\circ} \mathrm{C} \text { for } 30 \mathrm{~min} \\
\mathrm{CQDs} / \mathrm{ZnO}: \\
\mathrm{Zn}\left(\mathrm{CH}_{3} \mathrm{COO}\right)_{2} \cdot 2 \mathrm{H}_{2} \mathrm{O} \\
+\mathrm{CQDs}, \text { heated at } 80 \\
{ }^{\circ} \mathrm{C} \text { for } 3 \mathrm{~h}\end{array}$ & $\begin{array}{c}\text { CQDs/ZnO (200 } \\
\left.{ }^{\circ} \mathrm{C}\right) \text { degraded } 94 \% \\
\text { of } \mathrm{RhB}\end{array}$ & $\mathrm{Rh} B$ & $\begin{array}{c}105 \mathrm{~min}, \\
\text { xenon arc } \\
\text { lamp }(\lambda>420 \\
\mathrm{nm})\end{array}$ & $\begin{array}{c}\text { Bozetine } \\
\text { et al., } \\
2016\end{array}$ \\
\hline CQDs/BiOBr & $\begin{array}{c}\text { hydrotherma } \\
1\end{array}$ & $\begin{array}{c}{\left[\mathrm{C}_{16} \operatorname{mim}\right] \mathrm{Br}+} \\
\mathrm{Bi}\left(\mathrm{NO}_{3}\right)_{3} \cdot 5 \mathrm{H}_{2} \mathrm{O}+ \\
\left.\mathrm{HNO}_{3} \text { (to adjust } \mathrm{pH}\right), \\
\text { stirred at } \mathrm{RT} \text { for } 0.5 \\
\mathrm{~h} \text {, heated at } 140{ }^{\circ} \mathrm{C}\end{array}$ & $\begin{array}{c}\text { Photodegradation } \\
\text { for } \mathrm{CQDs} / \mathrm{BiOBr} \text { of } \\
\mathrm{TC} \text { and } \mathrm{RhB} \text { was } 4 \\
\text { times that of pristine } \\
\mathrm{BiOBr}\end{array}$ & $\begin{array}{l}\text { TC, } \\
\text { BPA, } \\
\text { Rh B }\end{array}$ & $\begin{array}{l}300 \mathrm{~W} \text { Xenon } \\
\text { lamp with a } \\
\text { cutoff filter } \\
((\lambda=400 \mathrm{~nm})\end{array}$ & $\begin{array}{c}\text { Ji et al., } \\
2018\end{array}$ \\
\hline
\end{tabular}




\begin{tabular}{|c|c|c|c|c|c|c|}
\hline & & for $24 \mathrm{~h}$ & & & & \\
\hline $\begin{array}{c}\mathrm{CQDs} / \mathrm{Bi}_{2} \mathrm{WO} \\
6\end{array}$ & $\begin{array}{l}\text { CQDs/Bi } i_{2} \mathrm{~W} \\
\mathrm{O}_{6}: \\
\text { Hydrotherm } \\
\text { al }\end{array}$ & $\begin{array}{c}\mathrm{CQDs} / \mathrm{Bi}_{2} \mathrm{WO}_{6}: \\
\mathrm{Na}_{2} \mathrm{WO}_{4} \cdot 2 \mathrm{H}_{2} \mathrm{O}+ \\
\mathrm{Bi}\left(\mathrm{NO}_{3}\right) 3.5 \mathrm{H}_{2} \mathrm{O}+ \\
\mathrm{CQDs}+\mathrm{HNO}_{3}, 140 \\
{ }^{\circ} \mathrm{C} \text { for } 24 \mathrm{~h}\end{array}$ & $\begin{array}{l}\text { Degradation rate of } \\
2 \% \mathrm{CQDs} / \mathrm{Bi}_{2} \mathrm{WO}_{6} \\
\text { is } 1.8 \text { times more } \\
\text { than that of } \mathrm{Bi}_{2} \mathrm{WO}_{6}\end{array}$ & $\begin{array}{c}\mathrm{RhB}, \\
\mathrm{CIP}, \\
\mathrm{TC}, \\
\mathrm{BPA}\end{array}$ & $\begin{array}{l}\text { Rh B: } 30 \mathrm{~min} \text {, } \\
\text { CIP: } 120 \mathrm{~min} \text {, } \\
300 \mathrm{~W} \text { xenon } \\
\text { lamp (400 nm } \\
\text { cutoff filter) }\end{array}$ & $\begin{array}{c}\text { Di et al., } \\
2015\end{array}$ \\
\hline CQDs/CdS & $\begin{array}{c}\text { CQDs: } \\
\text { electrochemi } \\
\text { cal } \\
\text { CQDs/CdS : } \\
\text { hydrotherma } \\
1\end{array}$ & $\begin{array}{c}\text { CQDs: ethanol + } \\
\text { water }+\mathrm{NaOH}+ \\
\text { graphite rods }+ \\
\mathrm{MgSO}_{4} \text {, stirred for } 20 \\
\text { min } \\
\mathrm{CQDs}^{2} \mathrm{CdS}: \\
\mathrm{Cd}\left(\mathrm{NO}_{3}\right)_{2} \cdot 4 \mathrm{H}_{2} \mathrm{O}+ \\
\text { thiourea }+ \\
\text { glutathione, heated at } \\
200{ }^{\circ} \mathrm{C} \text { for } 3.5 \mathrm{~h}\end{array}$ & $\begin{array}{c}\text { Degradation } \\
\text { efficacy of RhB was } \\
\text { found to be about } \\
90 \% \text { with } 1 \% \\
\text { C/CdS and } 50 \% \\
\text { with bare CdS }\end{array}$ & Rh B & $\begin{array}{c}1 \mathrm{~h}, 300 \mathrm{~W} \\
\text { tungsten } \\
\text { halide lamp } \\
\text { with cutoff } \\
\text { filter }(\lambda>400 \\
\mathrm{nm})\end{array}$ & $\begin{array}{c}\text { Liu et al., } \\
2013 b\end{array}$ \\
\hline $\begin{array}{c}\text { CQDs/Bi }{ }_{2} \mathrm{Mo} \\
\mathrm{O}_{6}\end{array}$ & $\begin{array}{c}\mathrm{CQDs} / \mathrm{Bi}_{2} \mathrm{M} \\
\text { oO }_{6}: \\
\text { Hydrotherm } \\
\text { al } \\
\mathrm{Bi}_{2} \mathrm{MoO}_{6}: \\
\text { solvotherma } \\
1\end{array}$ & $\begin{array}{l}\text { CQDs: glucose + DI, } \\
\text { heated at } 160{ }^{\circ} \mathrm{C} \text { for } 6 \\
\text { h } \\
\mathrm{Bi}_{2} \mathrm{MoO}_{6} \text { : } \\
\mathrm{Bi}\left(\mathrm{CH}_{3} \mathrm{COOH}\right)_{3} .5 \mathrm{H}_{2} \\
\mathrm{O}+ \\
\left(\mathrm{NH}_{4}\right)_{6} \mathrm{Mo}_{7} \mathrm{O}_{24} \cdot 4 \mathrm{H}_{2} \mathrm{O} \\
+ \text { urea (in ethanol), } \\
\text { heated at } 160{ }^{\circ} \mathrm{C} \text { for } \\
10 \mathrm{~h} \\
\mathrm{CQDs} / \mathrm{Bi}_{2} \mathrm{MoO}_{6}: \\
\text { Glucose }+\mathrm{Bi}_{2} \mathrm{MoO}_{6} \text {, } \\
\text { heated at } 160{ }^{\circ} \mathrm{C} \text { for } 6 \\
\mathrm{~h}\end{array}$ & $\begin{array}{c}\text { Degradation of } \\
\text { RhB: } 100 \% \text { over } \\
\text { CQDs/ } \mathrm{Bi}_{2} \mathrm{MoO}_{6} \\
(0.1 \text { glucose }) \text { and } 85 \\
\% \text { over bare } \\
\mathrm{Bi}_{2} \mathrm{MoO}_{6} \\
\text { MB: } 100 \% \text { over } \\
\text { CQDs/ } \mathrm{Bi}_{2} \mathrm{MoO}_{6} \text { and } \\
91 \% \text { over bare } \\
\mathrm{Bi}_{2} \mathrm{MoO}_{6}\end{array}$ & $\begin{array}{c}\mathrm{RhB}, \\
\mathrm{MB}\end{array}$ & $\begin{array}{c}300 \mathrm{~W} \text { xenon } \\
\text { lamp }(\lambda>420 \\
\mathrm{nm})\end{array}$ & $\begin{array}{c}\text { Sun et } \\
\text { al., } 2017\end{array}$ \\
\hline
\end{tabular}




\begin{tabular}{|c|c|c|c|c|c|c|}
\hline $\mathrm{CQDs} / \mathrm{KNbO}_{3}$ & $\begin{array}{l}\text { hydrotherma } \\
1 \text { and mixed- } \\
\text { calcination }\end{array}$ & $\begin{array}{l}\text { CQDs: L-Ascorbic } \\
\text { acid + glycol, heated } \\
\text { at } 160{ }^{\circ} \mathrm{C} \text { for } 70 \mathrm{~min} \\
\mathrm{CQDs} / \mathrm{KNbO}_{3}: \\
\mathrm{KNbO}_{3}+\mathrm{CQDs} \\
\text { solution, stirred at RT } \\
\text { for } 30 \text { min }\end{array}$ & $\begin{array}{c}\text { degradation rate for } \\
\mathrm{CQD} / \mathrm{KNbO}_{3} \text { of } \\
\text { crystal violet was } 70 \\
\% \text { and } 41.50 \% \text { for } \\
\text { pure } \mathrm{KNbO}_{3}\end{array}$ & $\begin{array}{c}\text { crystal } \\
\text { violet }\end{array}$ & $\begin{array}{c}5 \mathrm{~h}, 300 \mathrm{~W} \\
\text { Xenon lamp } \\
\text { with cut-off } \\
\quad \text { filter }\end{array}$ & $\begin{array}{c}\text { Qu et al., } \\
2018 b\end{array}$ \\
\hline $\begin{array}{c}\text { CQDs/BiOCl/ } \\
\mathrm{BiOBr}\end{array}$ & $\begin{array}{l}\text { CQDs/BiOC } \\
\text { 1/BiOBr: } \\
\text { solvent- } \\
\text { thermal }\end{array}$ & $\begin{array}{c}\text { CQDs: Citric acid + } \\
\text { ethylene diamine, } \\
\text { heated at } 200{ }^{\circ} \mathrm{C} \text { for } 5 \\
\mathrm{~h} \\
\mathrm{CQDs} / \mathrm{BiOCl} / \mathrm{BiOBr} \text { : } \\
\mathrm{CQDs}+ \\
\mathrm{Bi}\left(\mathrm{NO}_{3}\right)_{3} \cdot 5 \mathrm{H}_{2} \mathrm{O}+ \\
\text { mannitol solution }+ \\
{\left[\mathrm{C}_{16} \mathrm{mim}\right] \mathrm{Cl}+} \\
{\left[\mathrm{C}_{16} \mathrm{mim}^{\mathrm{mBr}} \text {, heated at }\right.} \\
140^{\circ} \mathrm{C} \text { for } 24 \mathrm{~h}\end{array}$ & $\begin{array}{c}5 \text { wt } \% \\
\text { CQDs/BiOCl/BiOB } \\
\text { r composite have } \\
2.1,2.8 \text { and } 3.0 \\
\text { times higher } \\
\text { degradation abilities } \\
\text { than } \mathrm{BiOCl} / \mathrm{BiOBr} \text {, } \\
\mathrm{BiOBr} \text { and } \mathrm{BiOCl}\end{array}$ & $\begin{array}{l}\mathrm{RhB}, \\
\mathrm{TC}, \\
\mathrm{BPA}, \\
\mathrm{CIP}\end{array}$ & $\begin{array}{l}250 \text { W Xenon } \\
\text { lamp with a } \\
400 \text { nm cutoff } \\
\text { filter }\end{array}$ & $\begin{array}{c}\text { Hu et al., } \\
2018\end{array}$ \\
\hline $\begin{array}{c}\mathrm{CdS} / \mathrm{CQD} / \mathrm{Bi} \\
\mathrm{OCl}\end{array}$ & $\begin{array}{c}\text { CQDs: } \\
\text { hydrotherma } \\
1 \\
\text { CdS/CQDs/ } \\
\text { BiOCl: } \\
\text { region- } \\
\text { selective } \\
\text { deposition }\end{array}$ & $\begin{array}{c}\text { CQDs: glucose + DI, } \\
\text { heated at } 160{ }^{\circ} \mathrm{C} \text { for } 3 \\
\mathrm{~h} \\
\mathrm{CdS} / \mathrm{CQDs} \text { : TGA + } \\
\mathrm{CdCl}_{2} \cdot 2.5 \mathrm{H}_{2} \mathrm{O}+ \\
\mathrm{NaOH} \text { (to adjust pH), } \\
\text { stirred at } 60{ }^{\circ} \mathrm{C} \text { for } 1 \\
\mathrm{~h} \\
\mathrm{CdS} / \mathrm{CQDs} / \mathrm{BiOCl} \text { : } \\
\mathrm{CQDs} / \mathrm{BiOCl} \text { powder } \\
+\mathrm{DI}+\mathrm{CdS} / \mathrm{CQDs} \\
\text { solution }+ \\
\mathrm{CQDs} / \mathrm{BiOCl}\end{array}$ & $\begin{array}{c}\text { degradation ratio of } \\
\text { phenol for } \\
\text { CdS/CQDs/BiOCl } \\
\text { was } 99.5 \% \text {. }\end{array}$ & $\begin{array}{c}\text { RhB } \\
\text { and } \\
\text { phenol }\end{array}$ & $\begin{array}{c}105 \text { min } \\
\text { (phenol), } 500 \\
\text { W Xenon } \\
\text { lamp with } 400 \\
\text { nm cut off } \\
\text { filter and } 500 \\
\text { W mercury } \\
\text { lamp }\end{array}$ & $\begin{array}{c}\text { Pan et al., } \\
2018\end{array}$ \\
\hline $\begin{array}{c}\mathrm{CQD} / \mathrm{Ag} / \mathrm{Ag}_{2} \\
\mathrm{O}\end{array}$ & $\begin{array}{c}\text { CQDs: } \\
\text { ultrasonic } \\
\text { CQDs/Ag/A } \\
\mathrm{g}_{2} \mathrm{O}: \\
\text { precipitation }\end{array}$ & $\begin{array}{c}\text { CQDs: glucose+ } \\
\mathrm{NaOH} \text {, ultrasonic for } \\
3 \mathrm{~h}+\mathrm{HCl}(\mathrm{pH}=7) \\
\mathrm{CQDs} \mathrm{Ag} / \mathrm{Ag}_{2} \mathrm{O} \text { : } \\
\mathrm{AgNO}_{3}+\mathrm{CQDs} \\
\text { solution }+\mathrm{NaBH}_{4}+ \\
\mathrm{NaOH}(\mathrm{pH}=11)\end{array}$ & $\begin{array}{c}\mathrm{CQDs} / \mathrm{Ag} / \mathrm{Ag}_{2} \mathrm{O} \text { had } \\
40 \% \text { improved } \\
\text { photocatalytic } \\
\text { action compared to } \\
\text { pure } \mathrm{Ag}_{2} \mathrm{O}\end{array}$ & $\begin{array}{l}\text { MB, } \\
\text { RhB }\end{array}$ & $\begin{array}{c}80 \text { min, } 250 \\
\text { W xenon lamp } \\
\text { as visible light } \\
\text { source, } 150 \mathrm{~W} \\
\text { infrared lamp } \\
\text { as NIR light } \\
\text { source }\end{array}$ & $\begin{array}{l}\text { Chen et } \\
\text { al., } 2016\end{array}$ \\
\hline
\end{tabular}




\begin{tabular}{|c|c|c|c|c|c|c|}
\hline $\begin{array}{l}\mathrm{TiO} 2 / \mathrm{BiOI} / \mathrm{C} \\
\text { QDs (TBC) }\end{array}$ & $\begin{array}{c}\text { CQDs: } \\
\text { Hydrotherm } \\
\text { al }\end{array}$ & $\begin{array}{l}\text { TBC: } \mathrm{TiO}_{2}, \mathrm{CQDs}+ \\
\text { EG Solution }+\mathrm{BiNO}_{3} \\
+\mathrm{KI} \text {, stirred for } 1 \mathrm{~h} \text { at } \\
\mathrm{RT} \text {, kept at } 40^{\circ} \mathrm{C} \text { for } \\
3 \mathrm{~h}\end{array}$ & $\begin{array}{l}\text { TBC showed } 2 \\
\text { times more } \\
\text { degradation rate } \\
\text { than P25 }\end{array}$ & $\mathrm{MO}$ & $\begin{array}{c}500 \mathrm{~W} \text { xenon } \\
\text { lamp }\end{array}$ & $\begin{array}{l}\text { Qu et al., } \\
\text { 2018a }\end{array}$ \\
\hline $\begin{array}{c}\mathrm{Ag} / \mathrm{CQDs} / \mathrm{Bi}_{2} \\
\mathrm{O}_{2} \mathrm{CO}_{3}\end{array}$ & $\begin{array}{c}\mathrm{Ag} / \mathrm{CQDs} / \mathrm{B} \\
\mathrm{i}_{2} \mathrm{O}_{2} \mathrm{CO}_{3}: \\
\text { photochemic } \\
\text { al reduction }\end{array}$ & $\begin{array}{c}\mathrm{Bi}_{2} \mathrm{O}_{2} \mathrm{CO}_{3}: 5 \mathrm{H}_{2} \mathrm{O}+ \\
\text { Citric acid }+\mathrm{HNO}_{3}+ \\
\mathrm{NaOH} \\
\mathrm{Ag} / \mathrm{Bi}_{2} \mathrm{O}_{2} \mathrm{CO}_{3}: \\
\mathrm{Bi}_{2} \mathrm{O}_{2} \mathrm{CO}_{3}+\mathrm{AgNO}_{3}, \\
60{ }^{\circ} \mathrm{C} \text { for } 12 \mathrm{~h}\end{array}$ & $\begin{array}{c}\mathrm{Ag} / \mathrm{CQDs} / \mathrm{Bi}_{2} \mathrm{O}_{2} \mathrm{CO} \\
{ }_{3} \text { showed } 1.91, \\
11.74,6.28 \text { times } \\
\text { more degradation } \\
\text { rate than } \mathrm{Bi}_{2} \mathrm{O}_{2} \mathrm{CO}_{3} .\end{array}$ & $\begin{array}{c}\mathrm{MB}, \mathrm{BP} \\
\mathrm{A}\end{array}$ & $\begin{array}{c}\text { Mercury } \\
\text { lamp, metal } \\
\text { halide lamp } \\
\text { with filter } \\
(420 \mathrm{~nm}) \text { and } \\
\text { without filter }\end{array}$ & $\begin{array}{l}\text { Zhang et } \\
\text { al., } 2019\end{array}$ \\
\hline $\begin{array}{c}\mathrm{Bi} / \mathrm{BiOCl} / \mathrm{TiO} \\
{ }_{2} / \mathrm{CQDs} \\
(\mathrm{BBTC})\end{array}$ & $\begin{array}{c}\text { CQDs: } \\
\text { Solvotherma } \\
1, \\
\text { Bi/BiOCl/Ti } \\
\mathrm{O}_{2} / \mathrm{CQDs} \\
\text { :hydrotherm } \\
\text { al }\end{array}$ & $\begin{array}{c}\mathrm{BiOCl} / \mathrm{TiO}_{2}: \\
\mathrm{Bi}\left(\mathrm{NO}_{3}\right)_{3} \cdot 5 \mathrm{H}_{2} \mathrm{O}+ \\
\mathrm{TiCl}_{4}+\text { ethylene } \\
\text { glycol }(+\mathrm{KCl})+ \\
\mathrm{PVP}, \text { heated at } 180 \\
{ }^{\circ} \mathrm{C} \text { for } 8 \mathrm{~h} \\
\\
\text { BBTC: } \mathrm{BiOCl} / \mathrm{TiO}_{2}+ \\
\text { citric acid }+ \text { ethylene } \\
\text { diamine, heated at } \\
180^{\circ} \mathrm{C} \text { for } 8 \mathrm{~h}\end{array}$ & $\begin{array}{c}\text { Degradation rate of } \\
\mathrm{Bi} / \mathrm{BiOCl} / \mathrm{TiO}_{2} / \mathrm{CQ} \\
\mathrm{Ds} \text { was } 10.3 \text { and } 4.8 \\
\text { times more than } \\
\mathrm{BiOCl} / \mathrm{TiO}_{2}\end{array}$ & $\begin{array}{l}\text { MO, } \\
\text { PNP }\end{array}$ & $\begin{array}{l}\text { MO: } 100 \mathrm{~min} \text {, } \\
\text { PNP: } 240 \mathrm{~nm} \text {, } \\
500 \mathrm{~W} \text { xenon } \\
\text { lamp }\end{array}$ & $\begin{array}{c}\text { Li et al., } \\
2018\end{array}$ \\
\hline $\begin{array}{c}\mathrm{CQDs} / \mathrm{Ag} / \mathrm{Ag}_{3} \\
\mathrm{PO}_{4}\end{array}$ & $\begin{array}{c}\text { CQDs: } \\
\text { electrochemi } \\
\text { cal }\end{array}$ & $\begin{array}{c}\text { CQDs: } \mathrm{NaOH}+ \\
\text { ethanol }+ \text { graphite } \\
\text { rods }+\mathrm{MgSO}_{4} \text {, stirred } \\
\text { for } 20 \mathrm{~min}, \mathrm{CQDs} \\
\text { obtained from silica- } \\
\text { gel column- } \\
\text { chromatography } \\
\mathrm{CQDs} / \mathrm{Ag} / \mathrm{Ag}_{3} \mathrm{PO}_{4} \text { : } \\
\mathrm{CH}_{3} \mathrm{COOAg}+\mathrm{PVP}+ \\
\mathrm{CQDs}+\mathrm{Na}_{2} \mathrm{HPO}_{4}, \\
\text { refluxed at } 90{ }^{\circ} \mathrm{C} \text { for } \\
3 \mathrm{~h}\end{array}$ & $\begin{array}{c}\text { Photocatalytic } \\
\text { action of CQDs/Ag/ } \\
\mathrm{Ag}_{3} \mathrm{PO}_{4} \text { was } 5.5 \\
\text { times that of } \\
\mathrm{Ag}_{3} \mathrm{PO}_{4}\end{array}$ & MO & $\begin{array}{c}10 \mathrm{~min}, 150 \\
\mathrm{~W} \text { xenon lamp } \\
\text { of }(\lambda<420 \\
\mathrm{nm} \text { or } 700 \\
\mathrm{~nm})\end{array}$ & $\begin{array}{l}\text { Zhang et } \\
\text { al., } 2012\end{array}$ \\
\hline
\end{tabular}


2019-04-25

Carbon quantum dot supported semiconductor photocatalysts for efficient degradation of organic pollutants in water: a review

Sharma, Sheetal

Elsevier

Sharma S, Dutta V, Singh P, et al., (2019) Carbon quantum dot supported semiconductor photocatalysts for efficient degradation of organic pollutants in water: a review. Journal of Cleaner Production, Volume 228, August 2019, pp. 755-769

https://doi.org/10.1016/j.jclepro.2019.04.292

Downloaded from Cranfield Library Services E-Repository 